\title{
Micropropagación y determinación del número cromosómico de Puya trianae con fines de conservación y uso ornamental
}

\section{Micropropagation and determination of the chromosome number of Puya trianae for conservation and ornamental use}

\author{
Jennifer Andrea Castro ${ }^{1}$, Eyda Johanna Araque ${ }^{2 *}$, José Estiben Pacheco ${ }^{2}$, José Constantino Pacheco ${ }^{1}$ \\ 1 Universidad Pedagógica y Tecnológica de Colombia, Laboratorio de Cultivo de Tejidos Vegetales, BIOPLASMA-UPTC. Avenida Central del Norte 39-115 \\ Tunja, Colombia. \\ 2 Estudiante de Maestría en Ciencias Biológicas-UPTC, Universidad Pedagógica y Tecnológica de Colombia, Laboratorio de Cultivo de Tejidos Vegetales \\ BIOPLASMA-UPTC. Avenida Central del Norte 39-115, Tunja, Colombia. \\ ${ }^{*}$ Autor de correspondencia \\ Email Jennifer Andrea Castro-S: jencasaav@gmail.com. \\ Email Eyda Johanna Araque-B: eyda.araque@uptc.edu.co \\ Email José Estiben Pacheco-D: jose.pacheco@uptc.edu.co \\ Email José Constantino Pacheco-M: jocpach@gmail.com
}

\begin{abstract}
Resumen
Puya trianae se caracteriza por desarrollar una vistosa inflorescencia que la caracteriza como planta de uso ornamental. Aunque actualmente no se considera amenazada, debido al rápido deterioro de los ecosistemas donde habita, la supervivencia de sus poblaciones sí está amenazada; por dichas razones se desarrolló un protocolo de micropropagación, aplicable para su conservación y para producción masiva de plántulas con fines ornamentales, así como a la determinación de su número cromosómico. Para la multiplicación se utilizaron plántulas provenientes de semillas germinadas in vitro realizando cuatro ensayos para determinar tipo, concentración y tiempo de exposición de algunos reguladores, además de la escisión parcial o total de explantes. Durante la fase de enraizamiento se cultivaron brotes en MS/2 solo y/o suplementado con AIB y ANA; la aclimatización de las plántulas obtenidas se realizó en diferentes mezclas de tierra:turba:capote, en cuarto de crecimiento e invernadero. Los resultados mostraron que en MS+2.0 $\mathrm{mgL}^{-1}$ de TDZ durante 45 días se produjo la mayor cantidad de yemas y brotes que terminaron su desarrollo después de 90 días. Los brotes enraizaron en MS/2 cuantificándose $70 \%$ de enraizamiento. Se registró una viabilidad del $90 \%$ y una longitud de plántulas de $3.6 \mathrm{~cm}$ en tierra:turba después de 60 días de aclimatización. El conteo cromosómico se realizó en células meristemáticas radicales tratadas con colchicina al $0.5 \%$, fijadas en carnoy, hidrolizadas con HCL y con enzimas y teñidas con orceína acética, obteniéndose un número cromosómico de 50 , con cromosomas muy pequeños (aprox. $1.2 \mu \mathrm{m}$ ).
\end{abstract}

Palabras claves: Bromeliaceae; citogenética; diploide; propagación in vitro.

\section{Abstract}

Puya trianae is characterized for developing a colorful inflorescence, which turned it into an ornamental plant. Is not currently considered threatened, due to the fast habitat deterioration, populations survival is threatened; due to the last, we developed a micropropagation protocol, focused on its conservation and mass production for ornamental purpose, as well as the chromosome counting. For multiplication, seedlings from germinated seeds were used in vitro and we made four tests to determine the type, concentration and time of exposure of some regulators, as well as the partial or total explants excised. Throughout the rooting phase, shoots were grown in $\mathrm{MS} / 2$ alone and/or supplemented with IBA and NAA; the acclimatization of the obtained seedlings was carried out in different mixtures land:peat:capote, in a growth room and a greenhouse. Buds and shoots that finished their development during 45 days in MS+2.0 $\mathrm{mgL}^{-1}$ of TDZ were the majority, after three months of development. The shoots rooted in MS/2 quantifying a $70 \%$ of rooting. A $90 \%$ viability and a plantlets length of $3.6 \mathrm{~cm}$ in soil: peat after 60 days of transfer. We made a radical meristematic cells chromosomal counting treated with a $0.5 \%$ of colchicine fixed in carnoy, hydrolyzed with $\mathrm{HCL}$ and enzymes and stained with acetic orcein, obtaining a chromosome number of $2 n=50$, with very small chromosomes (aprox. $1.2 \mu \mathrm{m}$ ).

Key words Bromeliaceae; cytogenetics; diploid; propagation in vitro.

\section{Citación:}

Castro J.A., E.J. Araque, J.E. Pacheco, J.C. Pacheco. 2018. Micropropagación y determinación del número cromosómico de Puya trianae con fines de conservación y uso ornamental. Revista peruana de biología 25(3): 267 - 280 (Agosto 2018). doi: http://dx.doi.org/10.15381/rpb. v25i3. 15210

\section{Presentado: $\quad 14 / 01 / 2018$ \\ Aceptado: 21/07/2018}

Publicado online: $25 / 09 / 2018$
Información sobre los autores:

JACS concepción, diseño, toma de datos, análisis y redaccion del documento. EJA, redaccion del documento. JEP, redaccion del documento. JCPM, concepción, diseño, análisis y escritura del documento. Los autores no incurren en conflictos de intereses. 


\section{Introducción}

Las Bromelias se caracterizan por presentar una amplia gama de usos, desde especies comestibles, forrajeras, medicinales, hasta especies ornamentales (Miranda et al. 2007). Colombia registra unas 500 especies, siendo el segundo país con mayor diversidad de Bromelias después de Brasil, (Betancur \& García 2006). El género Puya es uno de los más representativos de esta familia y de la región neotropical; habita en altitudes de 2500 a 4000 m y ocupa diversos ambientes como bosques, selvas de neblina, pastizales, subpáramos y páramos (Grau et al. 2010).

En Colombia, se registran 36 especies de Puya de las cuales 28 son endémicas y 25 de estas presentan algún grado de amenaza de extinción por causas de restricción geográfica, vulnerabilidad de los ecosistemas que habitan, por la condición de pobreza de sus suelos y escasa superficie, actividades antrópicas como el desplazamiento de la frontera agrícola, quemas, deforestación, extracción ilegal de individuos para su comercialización y la potencial amenaza que se vierte sobre los ecosistemas de páramo debido al cambio climático (Betancur \& García 2006).

Puya trianae (Baker) es una especie habitante de Colombia, Ecuador y Venezuela. En Colombia, se encuentra distribuida en todas las cordilleras, asociada predominantemente a la vegetación de tipo pajonal (Vargas et al. 2014). En 1997 fue considerada como vulnerable (VU) en la lista roja de plantas amenazadas de la UICN (Walter \& Gillett 1998), y en 2006 fue catalogada En Preocupación Menor (LC) en el Libro Rojo de plantas de Colombia (Betancur \& García 2006).

Aunque actualmente, $P$. trianae no es considera con un alto grado de amenaza, la fuerte presión y el creciente y rápido deterioro de los ecosistemas donde habita, la pondrían en riesgo en un futuro cercano. Por lo tanto, el desarrollo de planes de conservación y recuperación del germoplasma vegetal surge como una estrategia de gran importancia para su conservación, y que a su vez sería aplicable a otras especies de Puya.

La biotecnología vegetal, a través del cultivo de tejidos y de la citogenética, proporciona un sistema rápido y confiable para la producción de un gran número de plantas genéticamente uniformes (Jha \& Ghosh 2005), además, estas técnicas tienen un papel importante en la producción de plántulas de especies hortícolas, de valor comercial y ornamental, así como de flora silvestre con propósito de conservación ex situ, generando material vegetal para restauración ecológica, introducción o reintroducción, en los casos en que la propagación tradicional de la especie sea muy lenta, no sea efectiva, tenga bajas tasas de multiplicación o la población sea extremadamente reducida (Benson 1999, Quiala et al. 2004).

Previamente, diversos protocolos de propagación in vitro en Bromeliaceae han sido reportados. Por ejemplo, en especies como Alcantarea imperialis (Carrière) Harms (Aoyama et al. 2012), Nidularium innocentii Lem. y N. procerum Lindman (Lopes da Silva et al. 2012), Ananas comosus (L.) Merr. (Al-saif et al. 2011, Scherer et al. 2013), Vriesea reitzii Leme \& A. Costa (Dal-Vesco et al. 2014), Dyckia distachya Hassler (Pompelli \& Guerra 2005) y más específicamente en Puya, en especies como Puya chilensis Molina (1995 citado por Fuenzalida 2003, Lopéz et al. 2001 citado por Cabello \& Suazo 2007), Puya santosii Cuatrec. (Pedroza \& Bejarano 2008) y Puya berteroniana Mez. (Viehmannova et al. 2016).
Estudios sobre citogenética en la familia Bromeliaceae son muy escasos, indicándose que tan solo se conoce información de aproximadamente el 12\% de sus especies (Cotias et al. 2004). Gitaí \& Benko-Iseppon (2006), en una revision del género Puya encuentran pocos trabajos de estudios citogéneticos, y observan que la mayoría de las especies estudiadas poseen un número cromosómico igual al reportado frecuentemente para la familia, con un nivel diploide de $2 \mathrm{n}=50$, en Puya cardenasii L.B. Smith, Puya raymondii Harms, Puya spathacea Mez, Puya coerulea Lindley, Puya mirabilis (Mez) L.B.Sm y Puya berteroniana (Viehmannova et al. 2016), y un número haploide de 25 cromosomas en Puya eryngioides Andre, Puya floccosa (Linden) E. Morren, Puya lilloi Castell, Puya sparthacea (Griseb.) Mez, a excepción de $P$. chilensis con un número diploide de 48 cromosomas; aunque hay uniformidad en el número de cromosomas, existen algunas excepciones lo cual hace importante la investigación citogenética en este género (Gitaí \& Benko-Iseppon 2006).

Considerando lo anteriormente descrito, es evidente que aún existe un gran vacío de información respecto al desarrollo de biotecnologías que contribuyan al conocimiento y conservación de Puya; por lo tanto, este trabajo se realizó con miras a contribuir al conocimiento de Puya trianae, aportando información sobre su número cromosómico que es importante para estudios taxonómicos y evolutivos (Poggio et al. 2010), y estableciendo un protocolo de micropropagación que permita su conservación y uso sustentable como planta ornamental.

\section{Material y métodos}

Área de estudio y determinación taxonómica del material vegetal.- El material vegetal para identificación taxonómica se colectó en el páramo del Parque Natural Municipal Ranchería en Paipa, sector la Cuchilla, también conocido como la Cuchilla Cerro las Cruces ubicado en el Retiro (Corregimiento de Palermo, Municipio de Paipa-Boyacá) y el Municipio de Sotaquirá al costado occidental de la vía Paipa-Palermo, entre 3200 y 3600 $\mathrm{m}$, con una extensión de 657 ha a $5^{\circ} 5^{\prime} 0.97^{\prime} \mathrm{N}$ y $73^{\circ} 0.8^{\prime} 38.2^{\prime \prime W}$ (Morales et al. 2011).

La revisión e identificación taxonómica del material vegetal se realizó en el Herbario de la Universidad Pedagógica y Tecnológica de Colombia (UPTC), utilizando las claves botánicas de la Flora Neotropical (Smith \& Downs 1974).

\section{Propagación in vitro.-}

Colecta y establecimiento de material vegetal: El material inicial consistió en semillas de $P$. trianae colectadas y trasladadas en bolsas plásticas al Laboratorio de Cultivo de Tejidos Vegetales Bioplasma-UPTC; para la asepsia superficial, en cámara de flujo laminar las semillas se sumergieron en agua destilada estéril y Tween 20' (v/v) durante 5 minutos con agitación continua; luego, se transfirieron a pequeñas bolsas de muselina, las cuales se introdujeron en un recipiente de vidrio de $100 \mathrm{~mL}$ que contenía una solución de hipoclorito de sodio ( $\mathrm{NaClO} 5.25 \% \mathrm{p} / \mathrm{v}$ ) al 20\% (v/v) más Tween 20' durante 20 minutos con agitación continua, posteriormente se enjuagaron tres veces con agua destilada estéril.

Las semillas asépticas se sembraron en recipientes de vidrio de $100 \mathrm{~mL}$, con alícuotas de $20 \mathrm{~mL}$ de medio basal MS (Murashige \& Skoog 1962) con sales diluidas a $1 / 4$ de su concentración, y se incubaron a $24 \pm 1{ }^{\circ} \mathrm{C}$ con iluminación continua $(70-80 \mu \mathrm{mol}$ $\mathrm{m}^{-2} \mathrm{~s}^{-1}$ ) suministrada por lámparas fluorescentes de $75 \mathrm{~W}$. El 
medio se solidificó con $7 \mathrm{~g} \mathrm{~L}^{-1}$ de agar y el pH se ajustó a 5.7 con $\mathrm{HCl}$ y/o $\mathrm{NaOH} 1 \mathrm{~N}$; luego se esterilizó en autoclave a 15 psi y $121{ }^{\circ} \mathrm{C}$ durante $20 \mathrm{~min}$.

Proliferación de yemas: Para la multiplicación de yemas se utilizó como explantes iniciales plántulas de $1.0-1.5 \mathrm{~cm}$, obtenidas de semillas germinadas en la etapa anterior, a las cuales se les eliminó la raíz; el medio base utilizado fue MS. El proceso de proliferación comprendió dos fases, estimulación y expresión, cada una con una duración de 45 días, a excepción de los tratamientos realizados para determinar los días necesarios para estimulación de yemas.

Con el fin de optimizar tanto la estimulación y/o formación de yemas como el desarrollo de brotes, se realizaron los siguientes ensayos:

- Ensayo I. Efecto de la combinación auxina/citoquinina y efecto del carbón activado. Se probó el efecto de las auxinas (concentración en $\left.\mathrm{mgL}^{-1}\right)$ : $\mathrm{AIB}(0.1$ y 1.0$) \mathrm{y}$ ANA (0.3 y 0.7); y las citoquininas: BA $(0.5,1.0$ y 2.0$)$, TDZ $(0.01,0.02$ y 0.05$)$, y KIN $(0.5,1.0$ y 2.0$)$ solas y combinadas, además del medio MS sin reguladores de crecimiento para un total de 50 tratamientos cada uno con 24 explantes. Para promover el desarrollo de brotes, durante la fase de expresión se ensayaron los medios MS y MS más $0.3 \%$ de carbón activado.

- Ensayo II. Efecto de altas concentraciones de citoquininas durante periodos variables. Se probó el efecto de $2.0 \mathrm{mgL}^{-1}$ de TDZ, $5.0 \mathrm{mgL}^{-1}$ de KIN y $5.0 \mathrm{mgL}^{-1} \mathrm{de}$ $\mathrm{BA}$, durante 15, 30 y 45 días, sobre la estimulación de yemas; se cultivaron 30 explantes por tratamiento. La fase de expresión se realizó en medio MS sin reguladores de crecimiento durante 45 días.

- Ensayo III. Efecto de concentraciones elevadas de TDZ, durante periodos cortos. En este ensayo se probó el efecto de 4.0 y $7.0 \mathrm{mgL}^{-1}$ de TDZ durante 7,14 y 21 días de estimulación; se cultivaron 30 explantes por tratamiento. La fase de expresión se realizó en medio MS sin reguladores de crecimiento durante 45 días.

- Ensayo IV. Efecto de la escisión longitudinal de explantes. Los explantes se estimularon en MS suplementado con $2.0 \mathrm{mgL}^{-1}$ de TDZ, evaluando dos tipos de escisión longitudinal: una escisión parcial, dejando unidas por la base las dos mitades y una escisión total separando completamente las dos mitades; además, se cultivaron explantes intactos. En cada tratamiento se cultivaron 30 explantes durante 45 días de estimulación y 45 días de expresión en MS sin reguladores de crecimiento.

En todos los ensayos de proliferación realizados se cuantificó: promedio de yemas por explante (número de yemas formadas al finalizar la fase de expresión), promedio de brotes por explante, longitud media de brotes y promedio de hojas por brote, además del porcentaje de explantes necrosados en el ensayo IV. Entendiendo como "yemas" estructuras elongadas con ápice redondeado sobresaliente del tejido y, como "brotes" yemas en desarrollo de $0.3 \mathrm{~cm}$ o más de longitud.

Enraizamiento de brotes: Se utilizaron brotes de longitud $\geq 1 \mathrm{~cm}$ obtenidos en la etapa de proliferación. Los medios para enraizamiento fueron MS con sales diluidas a $1 / 2$ de su concentración original, sin reguladores y suplementado con AIB o ANA en concentraciones de $0.5,1.0$ y $2.0 \mathrm{mgL}^{-1}$. Se cultivaron 20 brotes por tratamiento. En esta etapa se evaluó el porcentaje de brotes enraizados, número de raíces por brote y longitud de la raíz más larga después de 30 días de cultivo.

Endurecimiento: Las plántulas obtenidas en la etapa anterior se extrajeron de los recipientes de cultivo, con agua corriente se eliminó los restos de medio adheridos a la raíz y se transfirieron a dos sustratos compuestos por tierra:capote y tierra:turba en proporción 2:1. Se sembraron 40 plantas por sustrato, en bandejas de germinación cubiertas con papel extensible perforado (20 plantas por bandeja), a una distancia de $2 \mathrm{~cm}$. Las bandejas se mantuvieron en cuarto de incubación durante 15 días, con iluminación continua a $21 \pm 1{ }^{\circ} \mathrm{C}$. Posteriormente se transfirieron a invernadero y, de forma progresiva, se retiró el plástico extensible; luego se transfirieron a vasos plásticos con el mismo sustrato. Al inicio y al final del ensayo (después de 55 días) se cuantificó la longitud de las plántulas y el porcentaje de plántulas viables por tratamiento.

Análisis estadístico.- Los datos obtenidos en las etapas de propagación in vitro se analizaron mediante el programa STATGRAPHICS CENTURION XVI, realizando análisis de varianza unifactorial ANOVA. Para evaluar las diferencias significativas encontradas en los análisis de varianza se aplicó una prueba de comparación múltiple DHS (Diferencia Honestamente Significativa) de Tukey con un nivel de confianza del 95\% (las letras simbolizan y agrupan en orden decreciente los valores medios alcanzados de la letra a en adelante conforme a la similitud (entre tratamientos) y diferencias estadísticas entre grupos. Para los datos de porcentaje que requirieron transformación se utilizó $\operatorname{arcosen} \sqrt{(x / 100)}$.

\section{Conteo cromosómico.-}

Material vegetal: Se utilizaron raíces desarrolladas in vitro en la fase de enraizamiento, inducidas con $1.0 \mathrm{mgL}^{-1}$ de ANA y raíces desarrolladas en agua.

Determinación del número cromosómico: Entre las 10:00 y las 11:00 horas se colectaron de cada plántula de 5 a 7 ápices radicales de $0.5-1.5 \mathrm{~cm}$ de longitud. Los ápices se pretrataron con colchicina al $0.5 \%$ durante 5 horas a $19 \pm 1{ }^{\circ} \mathrm{C}$; se enjuagaron con agua destilada y se fijaron en Carnoy (Alcohol absoluto: ácido acético glacial en proporción 3:1) durante 24 horas a $4{ }^{\circ} \mathrm{C}$, luego, se enjuagaron dos veces con agua destilada, se hidrolizaron con HCL $1 \mathrm{~N}$ durante 10 minutos a $60{ }^{\circ} \mathrm{C}$ y se enjugaron con agua destilada estéril. Los ápices se trataron con un coctel enzimático de celulasa al $5 \%$, pectinasa al $1 \%$ y macerozima al $1 \%$, durante 10 - 15 minutos en oscuridad a 37 ${ }^{\circ} \mathrm{C}$. Posteriormente se enjuagaron con agua destilada estéril y se observaron al estereoscopio para escindir la zona meristemática, la cual se colocó en un porta objetos con orceína acética al 2\% por 10 minutos, se flameó evitando la ebullición del colorante y, finalmente, se colocó el cubre objetos. Para lograr células en un solo plano se golpeó la muestra con una barra de goma y, por último, se realizó el squash.

Las observaciones se realizaron en un microscopio Carl Zeiss y un Motic BA 310. El conteo de cromosomas se realizó en 10 células, con objetivo de $100 x$. El registro fotográfico se tomó con una cámara Motic Cam de 10 megapíxeles adaptable al 
microscopio y con una cámara Nikon 5100. Para la medición de las células se empleó el programa Motic Images Advanced 3.2.

\section{Resultados}

\section{Propagación in vitro.-}

Establecimiento de material vegetal: El protocolo y la concentración de $\mathrm{NaClO}(20 \% \mathrm{v} / \mathrm{v})$ aplicados para la desinfección superficial de semillas de $P$. trianae resultó $100 \%$ eficaz ya que no se observó contaminación en ninguno de los recipientes de cultivo y, además, todas las semillas cultivadas germinaron.

El medio de cultivo utilizado fue adecuado para los procesos germinativos; la composición nutricional del medio fue óptima y permitió obtener plántulas con $2-4$ hojas y una longitud promedio de $1.0 \mathrm{~cm}$.

Proliferación de yemas: estimulación y/o formación de yemas y desarrollo de brotes.

Ensayo I. Efecto de la combinación auxina/citoquinina y del carbón activado. Los tratamientos en MS sin reguladores de crecimiento y en aquellos suplementados con AIB, ANA y TDZ, adicionados a los medios de cultivo solos o combinados (auxina/citoquinina), no mostraron efecto aparente sobre el número de yemas formadas, brotes desarrollados por explante, longitud y número de hojas por brote, mientras que todos los tratamientos que contenían KIN sola o en combinación con AIB y/o ANA promovieron el desarrollo de yemas axilares y adventicias formadas a través de organogénesis directa; no obstante, al analizar las variables número de yemas formadas y brotes por explante se observó diferencias estadísticas significativas ( $p=$ $0.00, p=0.00$ ), presentándose un mayor número de yemas y de brotes en los tratamientos con una mezcla auxina/citoquinina que únicamente con citoquinina.

El tratamiento en el que se produjeron los mejores resultados fue el realizado con $0.3 \mathrm{mgL}^{-1}$ de ANA + $2.0 \mathrm{mgL}^{-1} \mathrm{de} \mathrm{KIN} \mathrm{(Fig.}$ 1a), seguido por el tratamiento con KIN sin auxina (Fig. 1b), en los que se formaron en promedio, 8.2 y 7.4 yemas y 1.6 y 1.4 brotes por explante, respectivamente (Tabla 1). Sin embargo, aunque se registró una alta formación de yemas, éstas exhibieron un desarrollo muy lento formando brotes de poca longitud y, en la mayoría de los casos, con un reducido número de hojas.
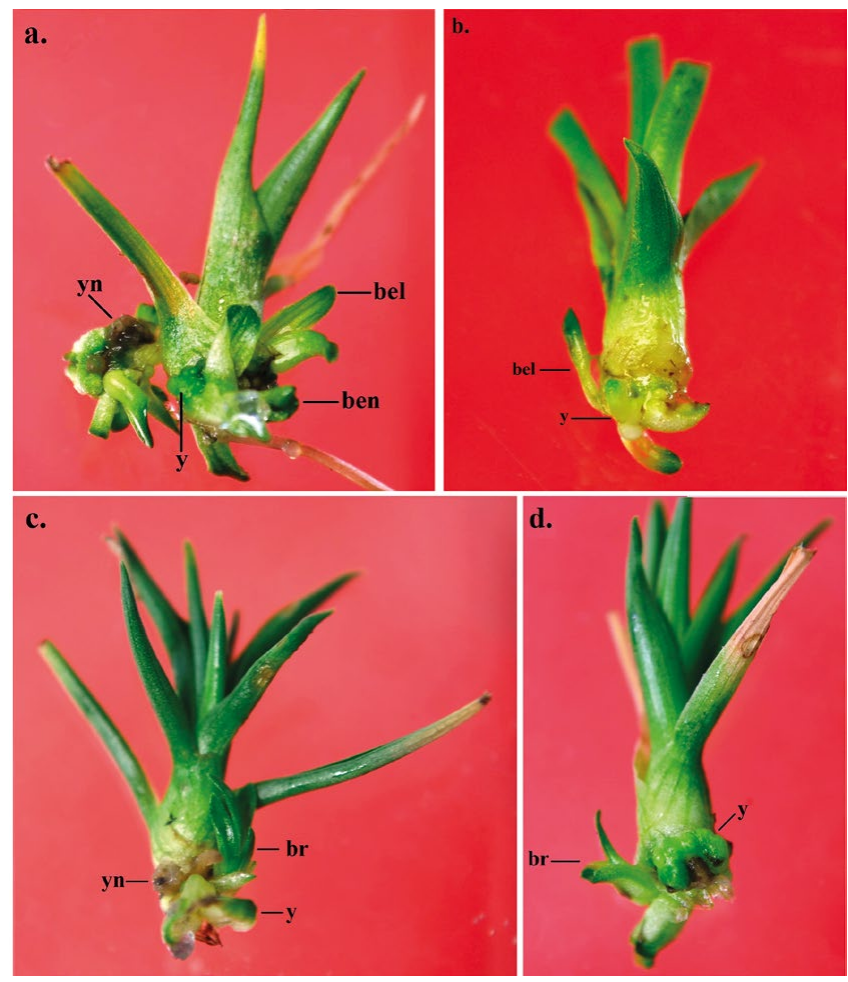

Figura 1. Yemas formadas y brotes desarrollados en presencia de: a. $0,3 \mathrm{mg} \mathrm{L}^{-1}$ de ANA + $2.0 \mathrm{mg} \mathrm{L}^{-1}$ de KIN; b. 2,0 $\mathrm{mg} \mathrm{L}^{-1}$ de $\mathrm{KIN}$; c. $0.7 \mathrm{mg} \mathrm{L}^{-1}$ de ANA + $1.0 \mathrm{mg} \mathrm{L}^{-1}$ de $\mathrm{KIN}$; d. $1.0 \mathrm{mg} \mathrm{L}^{-1} \mathrm{de}$ AIB + $1.0 \mathrm{mg} \mathrm{L}^{-1}$ de KIN. *br, brote normal; bel, brote elongado; ben, brote engrosado; y, yema; yn, yema necrosadas. Cada división de la escala $=1 \mathrm{~mm}$.

Tabla 1. Efecto de la combinación auxina/citoquinina sobre la formación de yemas, desarrollo de brotes por explante, longitud y número de hojas por brote, cuantificados a 90 días de iniciado el cultivo. Valores con letras distintas en una misma columna indica diferencias significativas según la prueba DHS de Tukey $(p \leq 0.05)$.

\begin{tabular}{|c|c|c|c|c|c|}
\hline$\underset{\left(\mathrm{mgL}^{-1}\right)}{\text { Auxina }}$ & $\underset{\left(\mathrm{mgL}^{-1}\right)}{\text { Citoquinina }}$ & $\begin{array}{l}\text { Promedio de yemas } \\
\text { por explante }\end{array}$ & $\begin{array}{c}\text { Promedio de } \\
\text { brotes por } \\
\text { explantes }\end{array}$ & $\begin{array}{l}\text { Promedio de } \\
\text { longitud por } \\
\text { brote }(\mathrm{cm})^{*}\end{array}$ & $\begin{array}{l}\text { Promedio de } \\
\text { hojas por brote } \\
\text { (cm)* }\end{array}$ \\
\hline \multirow{4}{*}{ AIB 0.1} & KIN 0.5 & $0.7 \mathrm{~g}$ & $0.2 \mathrm{ed}$ & * & * \\
\hline & KIN 1.0 & $3.2 \mathrm{defg}$ & $0.2 \mathrm{ed}$ & * & * \\
\hline & KIN 2.0 & 5.1 bcde & 0.8 abcde & $0.4 \mathrm{bc}$ & $1.4 \mathrm{bc}$ \\
\hline & KIN 0.5 & $1.3 \mathrm{fg}$ & 0.4 bced & * & * \\
\hline \multirow{2}{*}{ AIB 1.0} & KIN 1.0 & 4.3 cde & 0.9 abcde & $0.4 \mathrm{bc}$ & $2.4 \mathrm{~b}$ \\
\hline & KIN 2.0 & $6.2 \mathrm{abc}$ & 0.7 abcde & $0.5 \mathrm{ab}$ & $1.5 \mathrm{bc}$ \\
\hline \multirow{2}{*}{ ANA 0.3} & KIN 0.5 & $2.5 \mathrm{efg}$ & 0.3 cde & * & * \\
\hline & KIN 1.0 & $5.8 \mathrm{abcd}$ & $1.4 \mathrm{ab}$ & $0.4 \mathrm{bc}$ & $1.3 \mathrm{bc}$ \\
\hline \multirow{7}{*}{ ANA 0.7} & KIN 2.0 & $8.2 \mathrm{a}$ & $1.6 \mathrm{a}$ & $0.4 \mathrm{bc}$ & $1.3 \mathrm{bc}$ \\
\hline & KIN 0.5 & 3.6 cdef & 0.5 bcde & * & * \\
\hline & KIN 1.0 & $7.3 \mathrm{ab}$ & $1.1 \mathrm{abcd}$ & $0.5 \mathrm{a}$ & $3.8 \mathrm{a}$ \\
\hline & KIN 2.0 & $5.2 \mathrm{bcd}$ & $1.2 \mathrm{abcd}$ & $0.3 \mathrm{c}$ & $1.1 \mathrm{c}$ \\
\hline & KIN 0.5 & 4.1 cde & $0 \mathrm{e}$ & * & * \\
\hline & KIN 1.0 & $5.3 \mathrm{bcd}$ & 0.5 bcde & * & * \\
\hline & KIN 2.0 & $7.4 \mathrm{ab}$ & $1.4 \mathrm{abc}$ & $0.5 \mathrm{ab}$ & $1.2 \mathrm{c}$ \\
\hline
\end{tabular}

*El análisis de los datos de longitud y número de hojas por brote, solo se realizó para los tratamientos que produjeron una cantidad de brotes $>0.5$. 
Con respecto a las variables longitud y número de hojas por brote, teniendo en cuenta los tratamientos en los que se produjo una cantidad mayor de 0.5 brotes/explante, se observó diferencias significativas entre tratamientos $(p=0.00, p=0.00)$. La mayor longitud promedio alcanzada fue de $0.5 \mathrm{~cm}$ por brote, en los tratamientos con $2.0 \mathrm{mgL}^{-1}$ de KIN sola y en combinación con $1.0 \mathrm{mgL}^{-1}$ de AIB, además del realizado con $1.0 \mathrm{mgL}^{-1}$ de KIN + $0.7 \mathrm{mgL}^{-1}$ de ANA. En este último tratamiento los brotes formaron, en promedio, el mayor número de hojas, 3.8, (Fig. 1c), seguido por el tratamiento con $1.0 \mathrm{mgL}^{-1} \mathrm{de} A \mathrm{AB}+$ $1.0 \mathrm{mgL}^{-1}$ de KIN, con 2.4 hojas por brote (Fig. 1d) (Tabla 1).

Después de 90 días de cultivo se observaron yemas necrosadas y brotes malformados, en cantidades variables en los tratamientos con auxina/citoquinina, las cuales incrementaron en los tratamientos que contenían únicamente KIN. En general, los tratamientos en los que los brotes presentaron menor número de hojas, también formaron brotes malformados, principalmente brotes con una sola hoja elongada que, posteriormente, se desarrollaron normalmente; también se formaron, en menor cantidad, brotes malformados de aspecto engrosado sin formación de nuevas hojas; casi todos los brotes de este tipo se necrosaron a causa de hiperhidricidad. Estas malformaciones se presentaron en todos los tratamientos de los ensayos II, III y IV.

En cuanto al efecto de la adición o no de carbón activado en los medios de expresión, no hubo diferencias estadísticamente significativas con relación al número de brotes desarrollados por explante $(p=0.49)$ ni al número de hojas por brote $(p=0.07)$, registrándose 0.7 brotes y 2.0 hojas en presencia de carbón activado y 0.8 brotes y 1.6 hojas sin carbón activado. Sin embargo, respecto a longitud de brotes se encontró diferencias significativas $(p=0.00)$, siendo mayor en presencia de carbón activado, con promedio de $0.5 \mathrm{~cm}$ frente a $0.4 \mathrm{~cm}$ en su ausencia.

Ensayo II. Efecto de altas concentraciones de citoquininas durante periodos variables. Comparando el efecto de las diferentes citoquininas y los diferentes periodos de estimulación, se registraron diferencias significativas entre tratamientos $(p=0.00)$, estableciéndose una relación directamente proporcional entre el tiempo de estimulación y el número promedio de yemas, determinándose que a menor tiempo de estimulación, menor promedio de yemas, y viceversa, tanto en presencia de KIN como de TDZ.
Los tratamientos que produjeron la mayor cantidad promedio de yemas, 16.7 y 14.2 fueron los realizados con $2.0 \mathrm{mgL}^{-1} \mathrm{de}$ TDZ y $5.0 \mathrm{mgL}^{-1}$ de KIN, respectivamente, durante un periodo de 45 días; mientras que los tratamientos que mostraron el mayor desarrollo de brotes por explante, 5.0 y 2.9, fueron los realizados con $2.0 \mathrm{mgL}^{-1}$ de TDZ, durante periodos de 45 y 30 días, respectivamente. Además, el tratamiento con $5.0 \mathrm{mgL}^{-1} \mathrm{de}$ BA indujo respuesta solo cuando los explantes se estimularon durante 15 días, pero se produjo un número bajo tanto de yemas como de brotes (Tabla 2; Fig. 2).

El análisis de datos de longitud y número de hojas por brote mostraron diferencias significativas $(p=0.00, p=0.00)$, observándose la mayor longitud promedio $0.4 \mathrm{~cm}$ por brote cuando los explantes se trataron con KIN y TDZ durante 45 días; en
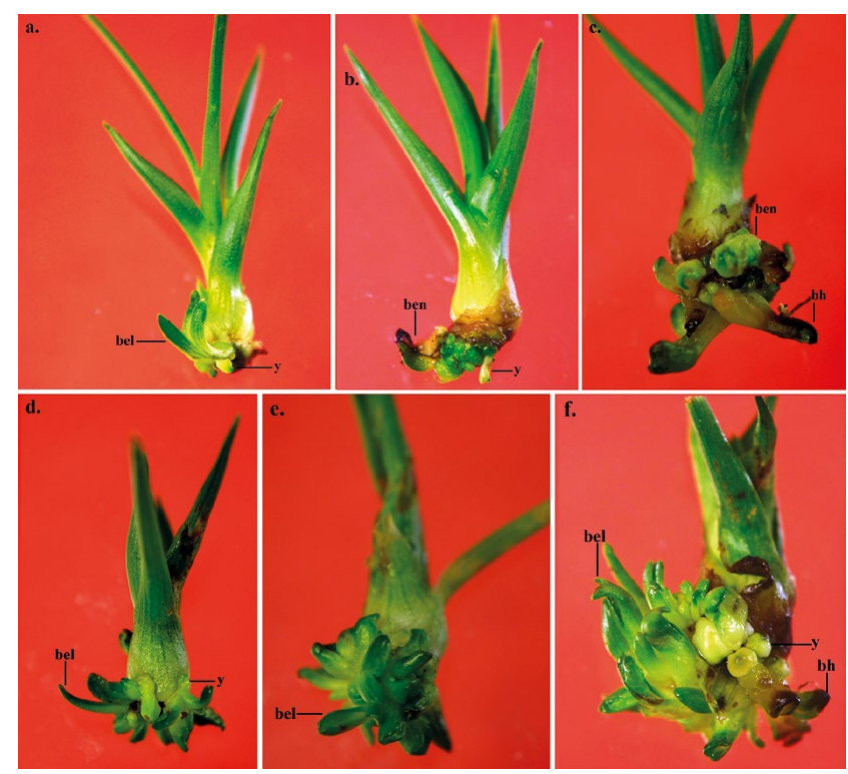

Figura 2. Yemas formadas y brotes desarrollados en presencia de $5,0 \mathrm{mg} \mathrm{L}^{-1}$ de KIN durante: a. 15 días, b. 30 días, c. 45 días, y de 2,0 $\mathrm{mg} \mathrm{L}^{-1}$ de TDZ durante: d. 15 días, e. 30 días, $\mathbf{f}$. 45 días. Obsérvese que a medida que aumentó el tiempo de estimulación se formó mayor número de yemas y se desarrolló mayor cantidad de brotes. *bel, brote elongado; ben, brote engrosado; bh; brote hiperhidratado; y, yema. Cada división de la escala $=1 \mathrm{~mm}$.

Tabla 2. Efecto de altas concentraciones de citoquininas durante periodos variables sobre estimulación de yemas, desarrollo y longitud de brotes y número de hojas por brote. Valores con letras distintas en una misma columna indica diferencias significativas según la prueba DHS de Tukey $(p \leq 0.05)$.

\begin{tabular}{|c|c|c|c|c|c|}
\hline $\begin{array}{l}\text { Citoquinina } \\
\left(\mathrm{mgL}^{-1}\right)\end{array}$ & Días de inducción & $\begin{array}{l}\text { Promedio de } \\
\text { yemas por } \\
\text { explante }\end{array}$ & $\begin{array}{l}\text { Promedio de brotes } \\
\text { por explantes }\end{array}$ & $\begin{array}{l}\text { Promedio de } \\
\text { longitud por } \\
\text { brote }(\mathrm{cm})^{*}\end{array}$ & $\begin{array}{l}\text { Promedio de hojas } \\
\text { por brote }(\mathrm{cm})^{*}\end{array}$ \\
\hline \multirow{4}{*}{ BA 5.0} & 15 & $0.6 \mathrm{~d}$ & $0.3 \mathrm{dc}$ & * & * \\
\hline & 30 & $0.0 \mathrm{~d}$ & $0.0 \mathrm{~d}$ & * & * \\
\hline & 45 & $0.0 \mathrm{~d}$ & $0.0 \mathrm{~d}$ & * & * \\
\hline & 15 & $4.6 \mathrm{c}$ & $0.2 \mathrm{dc}$ & * & * \\
\hline \multirow{2}{*}{ KIN 5.0} & 30 & $8.4 \mathrm{~b}$ & $0.3 \mathrm{dc}$ & * & * \\
\hline & 45 & $14.2 \mathrm{a}$ & $2.0 \mathrm{bc}$ & $0.4 \mathrm{a}$ & $1.2 \mathrm{c}$ \\
\hline \multirow{3}{*}{ TDZ 2.0} & 15 & $4.9 \mathrm{c}$ & $1.0 \mathrm{dc}$ & $0.2 \mathrm{~b}$ & $2.4 \mathrm{a}$ \\
\hline & 30 & $9.3 \mathrm{~b}$ & $2.9 \mathrm{~d}$ & $0.3 \mathrm{~b}$ & $1.3 \mathrm{bc}$ \\
\hline & 45 & $16.7 \mathrm{a}$ & $5.0 \mathrm{a}$ & $0.4 \mathrm{a}$ & $1.7 \mathrm{~b}$ \\
\hline
\end{tabular}

*El análisis de datos de longitud y número de hojas por brote, solo se realizó para los tratamientos que produjeron una cantidad de brotes > a 0.5 . 

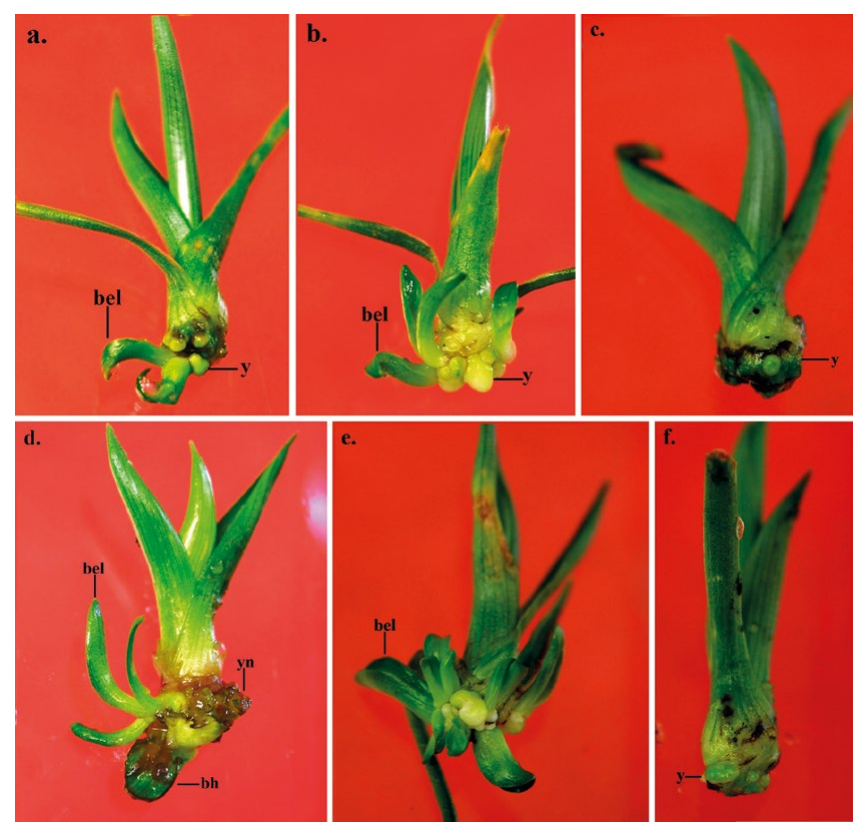

Figura 3. Yemas formadas y brotes desarrollados en presencia de $4 \mathrm{mg} \mathrm{L}^{-1}$ de TDZ durante: a. 7 días, b. 14 días, c. 21 días, y de 7,0 $\mathrm{mg} \mathrm{L}^{-1}$ de TDZ durante: $\mathbf{d}$. 7 días, e. 14 días, $\mathbf{f}$ 21 días. Obsérvese la escasa proliferación inducida durante 21 días en presencia de TDZ. *bel, brote elongado; bh; brote hiperhidratado; y, yema; yn, necrosada. Cada división de la escala $=1 \mathrm{~mm}$.

contraste, el tratamiento en el que se desarrolló el mayor número de hojas por brote (2.4) se realizó con $2.0 \mathrm{mgL}^{-1}$ de TDZ, durante el periodo más corto (15 días) (Tabla 2 ).

Aunque los mejores tratamientos para formación de yemas y desarrollo de brotes fueron los de 45 días de estimulación, al finalizar dicho periodo algunos brotes presentaron hiperhidricidad, con posterior necrosis de tejidos (Fig. 2c; 2f). En este ensayo, al igual que en el ensayo III y IV, también se evidenciaron brotes malformados, en mayor cantidad de tipo elongado y menor cantidad de tipo engrosado.

Ensayo III. Efecto de concentraciones elevadas de TDZ durante periodos cortos. Los análisis de varianza para las variables número de yemas y número de brotes por explante, establecieron diferencias significativas entre los diferentes tratamientos realizados $(p=0.00, p=0.00)$ siendo los mejores aquellos en los que los explantes se estimularon durante 14 días.
Al finalizar la etapa de expresión, el tratamiento que produjo un mayor promedio de yemas por explante, 15.8 , fue el realizado con $7.0 \mathrm{mgL}^{-1}$ de TDZ, seguido por el de $4.0 \mathrm{mgL}^{-1}$ de TDZ con un promedio de 11.9 yemas por explante; un mayor número de brotes por explante, 2.2 , se cuantificó en presencia de $4.0 \mathrm{mgL}^{-1}$ de TDZ, seguido por $7.0 \mathrm{mgL}^{-1}$ de TDZ durante periodos de estimulación de 7 y 14 días con 1.5 y 1.3 brotes respectivamente. Por otro lado, en los tratamientos de estimulación durante 21 días en presencia de 4.0 y $7.0 \mathrm{mgL}^{-1}$ de TDZ y 7 días con 4.0 $\mathrm{mgL}^{-1}$, se cuantificó la menor cantidad de brotes por explante (Tabla 3; Fig. 3).

Teniendo en cuenta los periodos de estimulación se observó que la longitud de los brotes registrada en presencia de cada una de las dos concentraciones de TDZ fue muy similar, por tanto, no se reportaron diferencias estadísticamente significativas entre estos tratamientos $(p=0.06)$; sin embargo, se registró mayor longitud promedio, $0.7 \mathrm{~cm}$, en el medio con $4.0 \mathrm{mgL}^{-1}$ de TDZ y un periodo de estimulación de 14 días. Los brotes presentaron mayor número de hojas en los medios con menor concentración de TDZ y/o en los tratamientos con periodos de inducción más cortos, 1.7 a 1.3 hojas por brote $(p=0.03)$ (Tabla 3 ).

Ensayo IV. Efecto de la escisión longitudinal de explantes. El tipo de escisión afectó tanto el número de yemas y brotes como la longitud de los mismos, presentándose diferencias significativas entre los tratamientos $(p=0.00, p=0.00, p=0.00)$. La estimulación y formación de yemas fue superior en aquellos explantes con escisión parcial, formando en promedio por explante, 40 yemas y 4.0 brotes que alcanzaron una longitud de $0.7 \mathrm{~cm}$ y presentaron 1.4 hojas, de apariencia engrosada; mientras que en explantes intactos y en aquellos en los que la escisión fue total se registró en promedio, 19.2 y 14.8 yemas, 2.3 y 0.7 brotes que alcanzaron una longitud de $0.4 \mathrm{~cm}$ y 1.6 hojas, respectivamente. No obstante, en los tres tratamientos hubo necrosis, 47, 43 y 7\% en explantes con escisión total, parcial y sin escindir, respectivamente (Fig. 4).

Aunque la mayoría de brotes obtenidos alcanzaron una longitud menor a $1 \mathrm{~cm}$ con pocas hojas desarrolladas, cuando permanecieron en MS sin reguladores de crecimiento durante 90 días, se pudo evidenciar un crecimiento y desarrollo normal, especialmente de aquellos brotes que inicialmente presentaban malformaciones relacionadas con elongación de la hoja, lo cual permitió individualizarlos fácilmente (Fig. 5); además, durante dicho periodo numerosas yemas se desarrollaron produciendo nuevos brotes.

Tabla 3. Efecto de altas concentraciones de TDZ durante periodos cortos de estimulación de yemas, desarrollo de brotes, longitud y número de hojas por brote. Promedios con letras distintas en una misma columna indica diferencias significativas según la prueba DHS de Tukey $(p \leq 0.05)$.

\begin{tabular}{|c|c|c|c|c|c|}
\hline $\begin{array}{l}\text { Citoquinina } \\
\left(\mathrm{mgL}^{-1}\right)\end{array}$ & Días de inducción & $\begin{array}{l}\text { Promedio de } \\
\text { yemas por } \\
\text { explante }\end{array}$ & $\begin{array}{l}\text { Promedio de brotes } \\
\text { por explantes }\end{array}$ & $\begin{array}{l}\text { Promedio de } \\
\text { longitud por } \\
\text { brote }(\mathrm{cm})^{*}\end{array}$ & $\begin{array}{c}\text { Promedio de hojas } \\
\text { por brote }(\mathrm{cm})^{*}\end{array}$ \\
\hline \multirow{3}{*}{ TDZ 4.0} & 7 & $9.0 \mathrm{~b}$ & $1.0 \mathrm{bc}$ & $0.5 \mathrm{a}$ & $1.7 \mathrm{a}$ \\
\hline & 14 & $11.9 \mathrm{ab}$ & $2.2 \mathrm{a}$ & $0.7 \mathrm{a}$ & $1.3 \mathrm{ab}$ \\
\hline & 21 & $11.1 \mathrm{~b}$ & $0.7 \mathrm{bc}$ & * & * \\
\hline \multirow{3}{*}{ TDZ 7.0} & 7 & $10.4 \mathrm{~b}$ & $1.3 \mathrm{abc}$ & $0.5 \mathrm{a}$ & $1.4 \mathrm{ab}$ \\
\hline & 14 & $15.8 \mathrm{a}$ & $1.5 \mathrm{ab}$ & $0.5 \mathrm{a}$ & $1.2 \mathrm{~b}$ \\
\hline & 21 & $10.2 \mathrm{~b}$ & $0.4 \mathrm{c}$ & * & * \\
\hline
\end{tabular}

${ }^{*}$ El análisis de los datos de longitud y número de hojas por brote, solo se realizó para los tratamientos que produjeron una cantidad de brotes $\geq$ a 1.0 . 

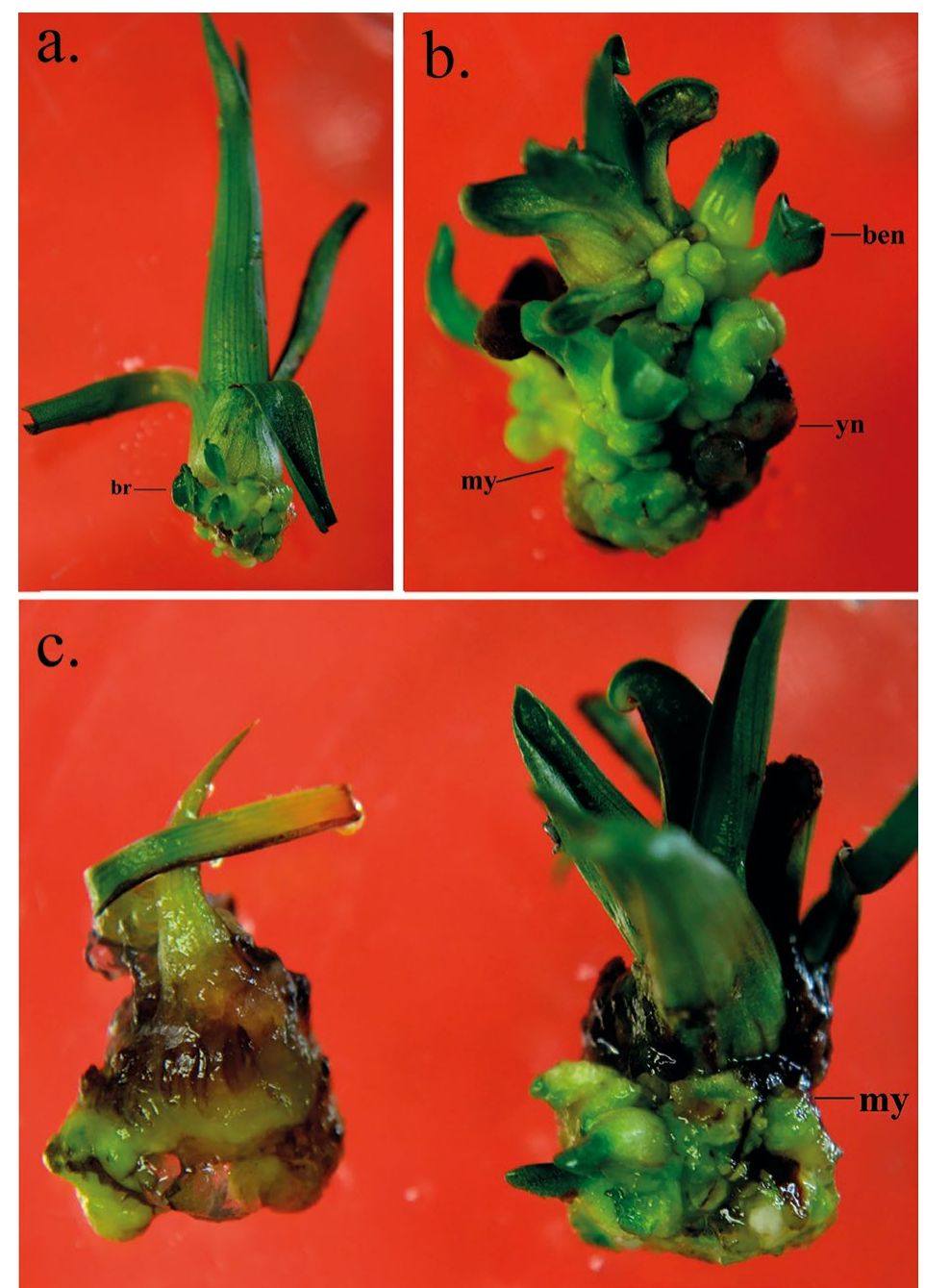

Figura 4. Yemas formadas y brotes desarrollados en explantes intactos y escindidos longitudinalmente, cultivados en presencia de $2,0 \mathrm{mg}$ $\mathrm{L}^{-1}$ de TDZ a. Explante intacto. b. Explante escindido parcialmente. c. Explante escindido totalmente (se muestran las dos partes del explante: izquierda, parte necrosada; derecha, parte viable y reactiva). *br, brotes; my, multiples yemas; yn, yemas necrosadas; ben, brote engrosado. Cada división de la escala $=1 \mathrm{~mm}$.
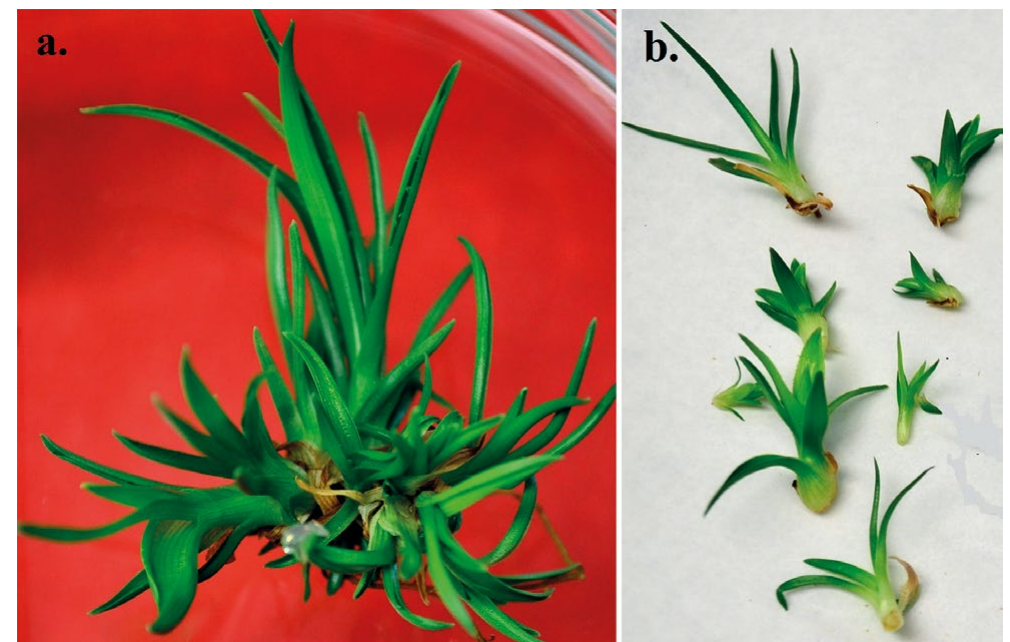

Figura 5. Brotes elongados en MS. a. Macollas de brotes desarrollados 90 días después de la fase de proliferación, b. Brotes individualizados. *Cada división de la escala $=1 \mathrm{~mm}$. 
Enraizamiento de brotes: Después de 30 días de cultivo en los medios para enraizamiento, los brotes mostraron efectos diferentes sobre las variables promedio y longitud de raíces $(p=$ $0.00, p=0.00)$, mientras que no se establecieron diferencias significativas para la variable porcentaje de brotes enraizados $(p=0.08)$. Los tratamientos que mostraron los promedios de enraizamiento más altos fueron los realizados con AIB $(80,79$ y $78 \%$ ), con un promedio de raíces de $3.8-6.2$, de $0.7 \mathrm{~cm}$ de longitud y de morfología delgada. En presencia de ANA, el porcentaje de enraizamiento fue más bajo, principalmente en las concentraciones más altas, sin embargo se cuantificó un alto promedio de raíces $(4.9-6.5)$, de apariencia gruesa y de longitud semejante a la registrada en presencia de AIB $(0.5-0.8 \mathrm{~cm})$. Por otro lado, las respuestas observadas en el medio sin reguladores de crecimiento (MS/2) para las tres variables evaluadas son, de manera general, semejantes a las cuantificadas en los medios con las mejores respuestas (Tabla 4; Fig. 6).

Endurecimiento: Después de 15 días de iniciada la aclimatización en los sustratos tierra:capote y tierra:turba, en proporción
(2:1), en condiciones de cuarto de incubación (Fig. 7a; 7b), se registró $100 \%$ de plántulas viables, mientras que después de 40 días en condiciones de invernadero (Fig. 7c; 7d), se cuantificó, un 73 y $90 \%$ de viabilidad, y un crecimiento de $0.9 \mathrm{~cm}$ (longitud promedio al inicio del ensayo de $2.2 \mathrm{~cm}$ y después de 40 días $3.1 \mathrm{~cm}$ ) y $1.4 \mathrm{~cm}$ (longitud promedio al inicio del ensayo de $2.2 \mathrm{~cm}$ y después de 40 días $3.6 \mathrm{~cm}$ ) en el sustrato compuesto por tierra:capote y tierra:turba, respectivamente. Finalmente, después de 120 días de endurecimiento, las plántulas alcanzaron, en promedio, $7.1 \mathrm{~cm}$ de longitud, presentaron numerosas hojas y espinas bien definidas (Fig. 7e; 7f).

\section{Conteo cromosómico.-}

Las raíces utilizadas para la observación de las diferentes etapas mitóticas en células meristemáticas, se caracterizaron por presentar tejidos con cierto grado de consistencia y una zona meristemática muy reducida en la cual se observaron muy pocas células en división.

Las características generales de las fases mitóticas observadas concuerdan con las reportadas para la mayoría de las especies
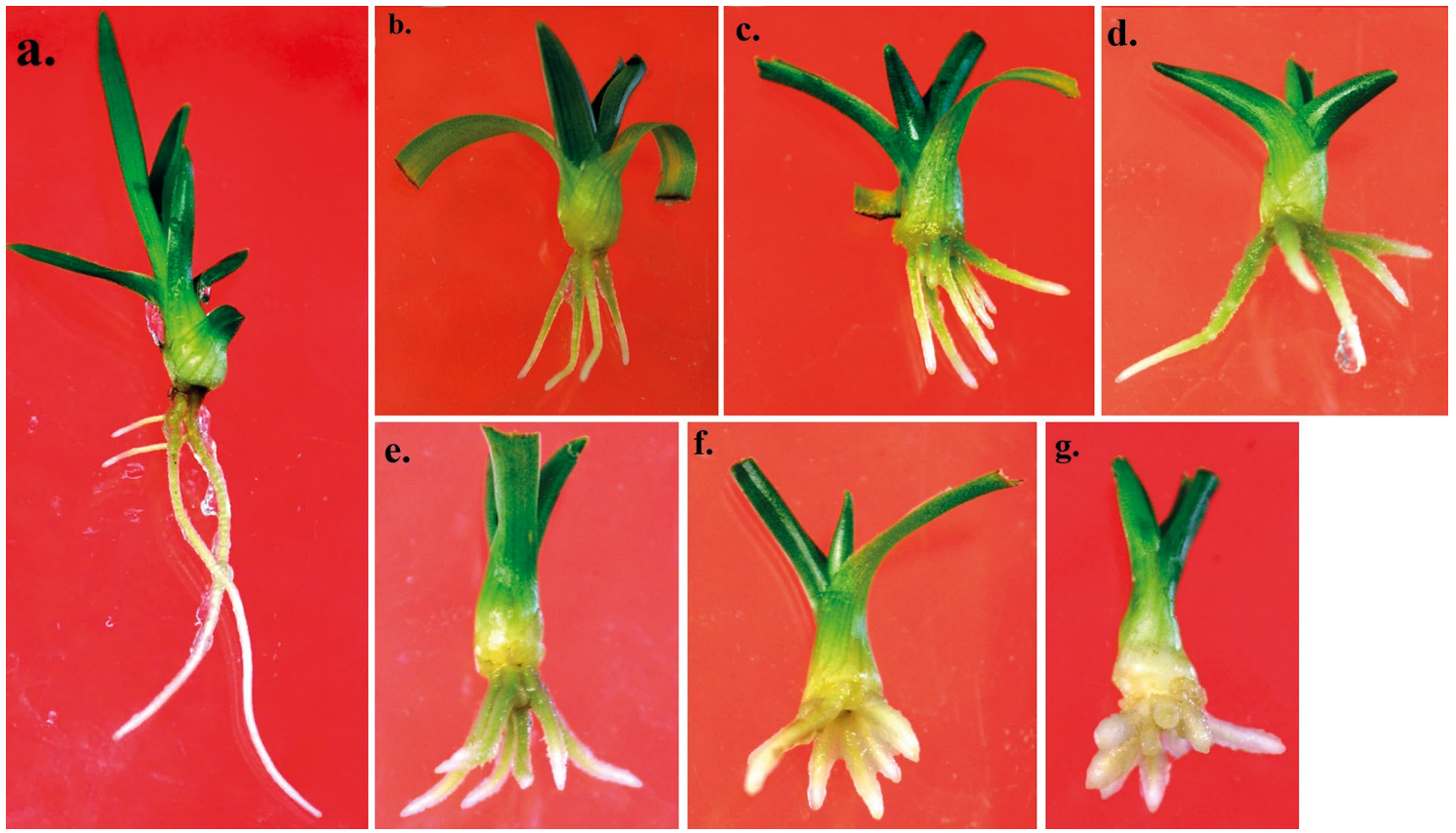

Figura 6. Brotes de $P$. trianae enraizados en MS/2: a. Sin auxina. b. con AIB 0,5 $\mathrm{mg} \mathrm{L}^{-1}$. c. con AIB $1,0 \mathrm{mg}$ $\mathrm{L}^{-1}$. d. con AIB 2,0 mg L-1. e. con ANA 0,5 mg L-1. f. con ANA 1,0 mg L-1. g. con ANA 2,0 $\mathrm{mg} \mathrm{L}^{-1}$. *Cada división de la escala $=1 \mathrm{~mm}$

Tabla 4. Enraizamiento de brotes de $P$. trianae en presencia de AIB y ANA.

\begin{tabular}{lccc}
\hline Tratamiento $\left(\mathbf{m g L}^{-1}\right)$ & Brotes enraizados $(\mathbf{\%})$ & $\begin{array}{c}\text { Promedio de longitud de la raíz / } \\
\text { brote }(\mathbf{c m})\end{array}$ & Promedio de raíces/brote \\
\hline MS/2 & $70 \mathrm{a}$ & $1.5 \mathrm{a}$ & $2.3 \mathrm{c}$ \\
$\mathrm{MS} / 2$ + AIB 0.5 & $79 \mathrm{a}$ & $0.8 \mathrm{~b}$ & $3.8 \mathrm{bc}$ \\
MS/2 + AIB 1.0 & $80 \mathrm{a}$ & $0.7 \mathrm{~b}$ & $5.0 \mathrm{ab}$ \\
MS/2 + AIB 2.0 & $78 \mathrm{a}$ & $0.7 \mathrm{~b}$ & $6.2 \mathrm{ab}$ \\
MS/2 + ANA 0.5 & $74 \mathrm{a}$ & $0.5 \mathrm{~b}$ & $4.9 \mathrm{a}$ \\
MS/2 + ANA 1.0 & $50 \mathrm{a}$ & $0.8 \mathrm{~b}$ & $6.3 \mathrm{a}$ \\
MS/2 + ANA 2.0 & $45 \mathrm{a}$ & $0.5 \mathrm{~b}$ & $6.5 \mathrm{a}$ \\
\hline
\end{tabular}

Promedios con letras distintas en la misma columna indican diferencia significativa según la prueba DHS de Tukey ( $p=0.05)$. 

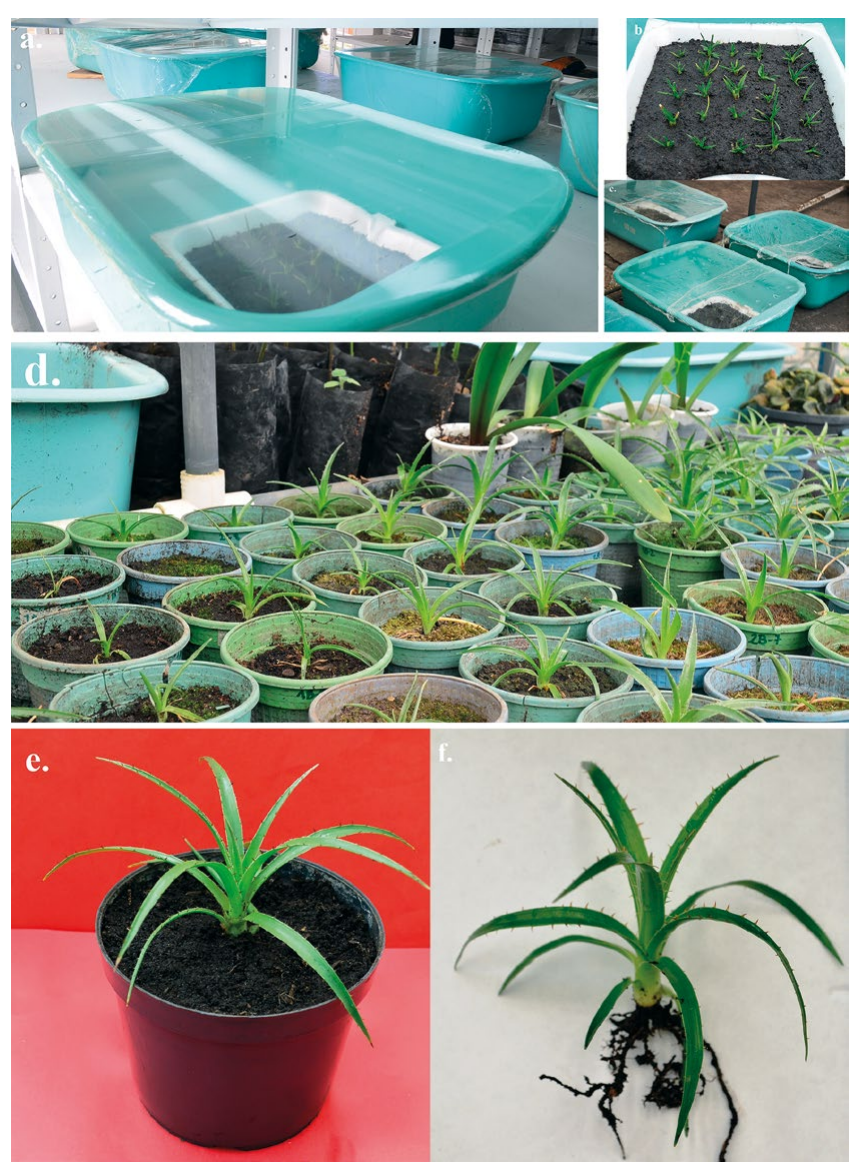

Figura 7. Aclimatización de plántulas de $P$. trianae. a y b. Plántulas en cuarto de incubación. c. Plántulas en invernadero. d. Plántulas en sustrato tierra/turba (2:1) después de 45 días de endurecimiento. e y f. Plántula de 4 meses. *Cada división de la escala $=5 \mathrm{~mm}$. vegetales; en la interfase se observó un núcleo celular bien definido que tiñe homogéneamente (Fig. 8a). En la profase se observó células sin membrana nuclear, los cromosomas se hicieron visibles en forma de filamentos cortos (Fig. 8b) que luego formaron estructuras más gruesas y compactas (Fig. 8c). Los cromosomas se desplazaron al plano ecuatorial en prometafase (Fig. 8d), y luego se observó el alineamiento de cromosomas o metafase (Fig. 8e; 8f). En anafase se observó la migración de cromosomas a los polos (Fig. 8g; $8 \mathrm{~h}$ ) y un nuevo agrupamiento en cada uno (Fig. 8i). En telofase se perdió la individualidad de los cromosomas y ocurrió la división del citoplasma mediante el proceso de tabicación (Fig. 8j; 8k; 8l).

Determinación del número cromosómico: El procedimiento seguido para el conteo de cromosomas en células de $P$. trianae fue adecuado y facilitó la dispersión y la visualización de dichos cromosomas; no obstante, debido al tamaño pequeño de los cromosomas, no fue posible realizar, de manera consistente, las mediciones correspondientes. Sin embargo, se pudo establecer que las células de $P$. trianae se caracterizan por tener 50 cromosomas que forman estructuras de apariencia esferoidal (debida a su corta longitud); el mayor tamaño registrado en mediciones preliminares fue de $1.2 \mu \mathrm{m}$ (Fig. 9).

\section{Discusión}

La desinfección de semillas fue $100 \%$ efectiva y concuerda con los resultados reportados por Alves (2000) y Soares (2009), quienes mencionan que en plantas de la familia Bromeliaceae, comúnmente, se han utilizado soluciones de $\mathrm{NaClO}$ de 1 a $20 \%$ para procesos de asepsia superficial de explantes. Así mismo, se registran resultados exitosos de establecimiento in vitro de Acanthostachys strobilacea (Schultes f.) Klotzsch (Soares 2009) y Melissa officinalis L. (Soares et al. 2008) en medios con sales reducidas a 1/2, 1/4 y

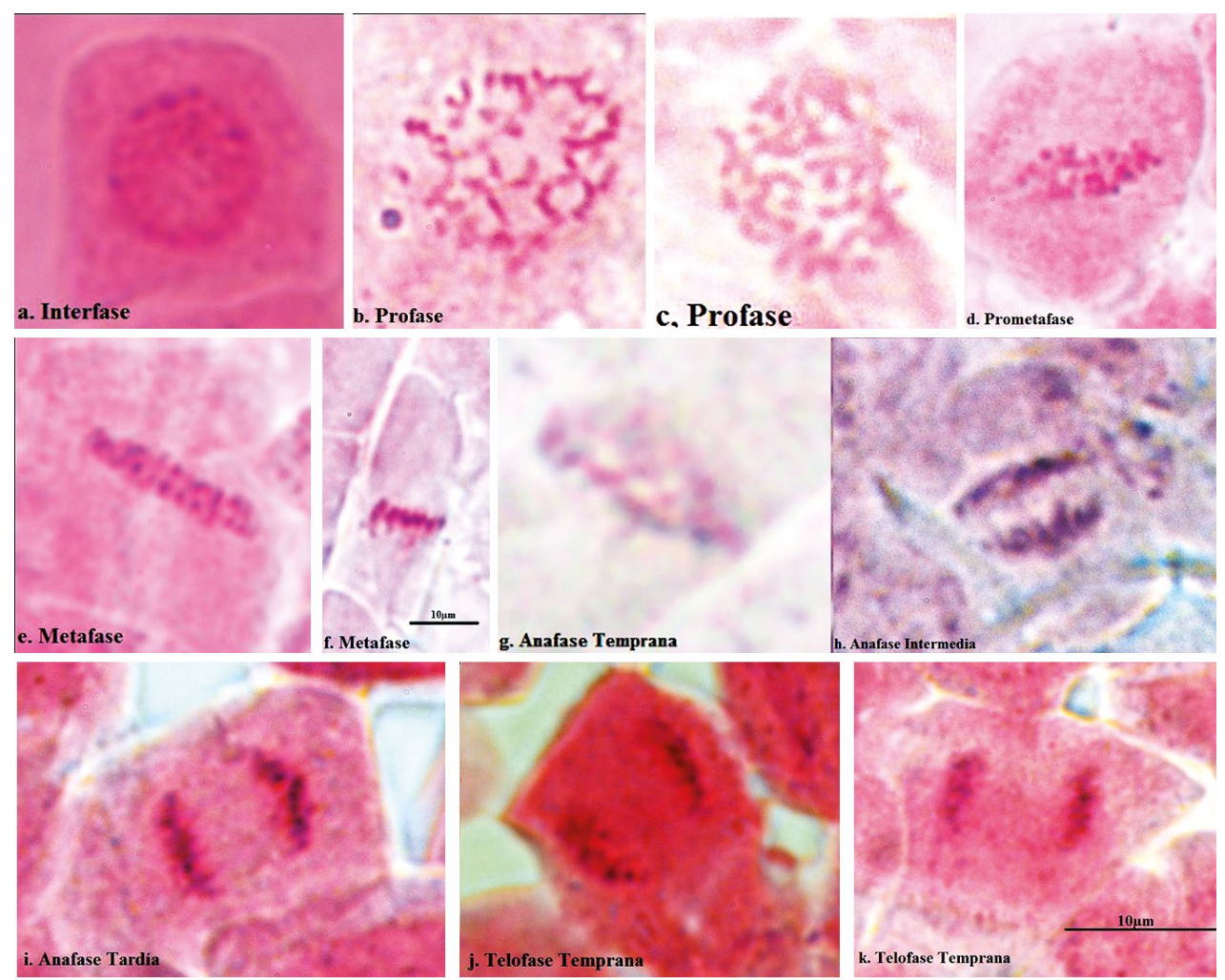

Figura 8. Fases mitóticas observadas en células de meristemos radicales de Puya trianae. *Vista 100X. 


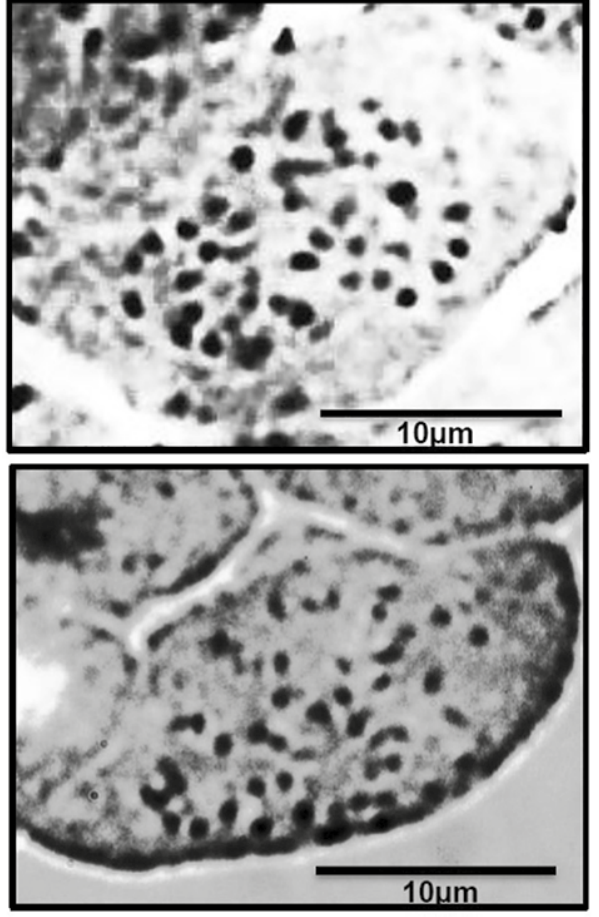

Figura 9. Células de tejido meristemático radical de Puya trianae, con cromosomas metafásicos. *Vista 100X.

$1 / 5$, en los cuales la cantidad reducida de nutrientes en el medio promueve mayor desarrollo de plántulas. Según Benzing \& Renfrow (1974), las especies de la familia Bromeliaceae tienen una alta afinidad por los minerales en soluciones muy diluidas, ya que se absorben rápidamente cuando están disponibles en el medio ambiente, tal como se observa en $P$. trianae, en la cual es evidente un adecuado desarrollo en presencia de bajas concentraciones de nutrientes, que es característica de su hábitat natural donde la disponibilidad en el suelo es baja (Llambí et al. 2012).

En cuanto a proliferación de brotes, los resultados mostraron que la presencia de reguladores de crecimiento es necesaria para la estimulación y formación de yemas y para desarrollo de brotes en $P$. trianae; además, el tipo de regulador, el periodo de estimulación y el balance auxina/citoquinina fueron adecuados, evidenciándose que una mayor concentración de citoquinina, respecto a la auxina, favoreció la división celular permitiendo una rápida síntesis de proteínas o enzimas estructurales importantes para la mitosis, generando respuestas relacionadas con crecimiento y desarrollo e inhibiendo el proceso de formación de raíces, tal como ha sido citado por algunos autores, entre ellos Gonçalves (2010), y en otras especies.

La estimulación de explantes con ANA y BA (solas o combinadas) ejercieron un efecto positivo sobre las variables estudiadas; no obstante, su actividad en cuanto a formación de yemas y desarrollo de brotes fue limitada, en contraste con la observada en presencia de KIN y TDZ ya que la exposición prolongada a estos reguladores produjo los mejores resultados (en mayor medida, en presencia de $2.0 \mathrm{mgL}^{-1}$ de TDZ).

En la familia Bromeliaceae es poco conocido el papel del TDZ sobre la regeneración de tejidos; en cambio, se conoce que numerosas especies reaccionan a combinaciones auxina/ citoquinina en especial BA, ANA o AIB, tal como se ha indicado en reportes sobre propagación in vitro de Puya chilensis (López et al. 2001 citado por Cabello \& Suazo 2007), Puya tuberosa Mez. (Morales et al. 2004 citado por Cabello \& Suazo 2007), Hohenbergia penduliflora (A.Rich.) Mez (Pérez et al. 2013) y Puya berteroniana (Viehmannova et al. 2016), en las cuales la adición de BA y ANA en los medios de cultivo ha sido asociada con eventos morfogenéticos que generan altas tasas de proliferación.

En un estudio realizado por Guo et al. (2011) sobre el efecto del TDZ como regulador de crecimiento vegetal, recopila información acerca de la regeneración de tejidos en cultivo in vitro tratados con TDZ en diferentes familias de plantas, pero no registra estudios para la familia Bromeliaceae. Sin embargo, el TDZ ha sido utilizado para cultivo de tejidos vegetales debido a que induce respuestas similares a las producidas por las citoquininas naturales, auxinas endógenas, etileno y ABA; además, estimula la generación de iones minerales y otros metabolitos que producen en el explante una condición de estrés que conduce a los tejidos a reformar sus vías metabólicas, resultando en el almacenamiento y síntesis de diferentes metabolitos que favorecen los procesos de regeneración. En tanto, según algunos autores, la adición de esta citoquinina, en comparación con otras normalmente utilizadas, en muchas especies genera respuestas debido a su potencial morfo-regulador durante el desarrollo de sistemas morfogenéticos viables (Guo et al. 2011), tal como sucedió en los explantes de $P$. trianae.

En el presente trabajo, los brotes obtenidos alcanzaron mayor longitud cuando los explantes primarios se estimularon durante periodos largos. Aunque dichos brotes formados se transfirieron durante 45 días a un medio libre de reguladores, es evidente que en esta especie los brotes necesitan un periodo de expresión más prolongado, puesto que numerosas yemas formadas no alcanzaron a desarrollar brotes al cabo de los 45 días, y que después de tres meses de mantener yemas y brotes proliferados en MS alcanzaron un buen desarrollo. Este resultado puede ser debido, en parte, al efecto residual que tiene el TDZ, principalmente por su composición basada en urea, no degradable en el tejido vegetal por la enzima citoquinina oxidasa, por lo que la proliferación de yemas y brotes continua en el medio libre de reguladores de crecimiento (Guo et al. 2011), contrario a lo planteado por Huetteman y Preece (1993), Castañeda (2008) y George et al. (2008) quienes sugieren que el uso de TDZ puede inhibir la elongación de los brotes, además de causar anormalidades morfológicas, hiperhidricidad y fasciación, como se observó en el ensayo III.

En el tercer ensayo se observó la tolerancia que tiene $P$. trianae a altas concentraciones de reguladores de crecimiento, principalmente de TDZ. Si bien se presentó una alta proporción de brotes malformados, al igual que en los ensayos I y II, en ninguno de los tratamientos se evidenció formación de callo, u oxidación de explantes. Los resultados mostraron que altas concentraciones y periodos relativamente largos de estimulación provocaron menor formación de yemas y desarrollo de brotes, debido, quizá, a que se sobre-pasó el rango máximo de tolerancia de las células. Este resultado es similar al observado en Laelia anceps Lindl., en la que altas concentraciones de TDZ inhibieron la formación de yemas y desarrollo de brotes (Castañeda 2008).

En consecuencia, es evidente la necesidad de ajustar adecuadamente el periodo de estimulación de los explantes según el tipo de regulador de crecimiento, siendo este un factor impor- 
tante, que hace posible la expresión de una mayor capacidad organogénica. No obstante, se debe considerar que la capacidad de regeneración depende principalmente del genotipo y de los niveles endógenos de reguladores de crecimiento encontrados en cada especie y de manera específica en los explantes utilizados para cultivo in vitro (Silveira et al. 2009).

De manera general, se conoce el efecto de los componentes del medio de cultivo sobre la multiplicación de brotes y, en particular, de las hormonas de crecimiento, las cuales han sido ampliamente estudiadas en numerosas especies vegetales; sin embargo, según Perez et al. (2010), el efecto positivo de los componentes también puede estar influenciado por la manipulación o seccionamiento de los tejidos, principalmente por cortes realizados a los explantes antes de cultivarlos. En Musa spp la multiplicación in vitro se efectúa escindiendo los explantes en dos mitades, con el fin de obtener tejido meristemático en cada parte (Pocasangre 1994 citado en Perez et al. 2010) y, en Ananas comosus (Suárez 2011), el sistema de corte ha resultado beneficioso para el aumento en la proliferación y producción de un mayor número de hojas; al respecto, Zamora y Juárez (2008), indican que existe otra ventaja al realizar cortes en los explantes, tal como un aumento de la cantidad de plantas obtenidas con morfología semejante.

Los resultados obtenidos en el ensayo IV indican que los efectos de la escisión de explantes son positivos para la formación de múltiples yemas, principalmente en el tratamiento en el que los explantes se escindieron parcialmente. Sin embargo, la escisión provocó la oxidación de explantes, lo cual, según Azofeifa (2009), es un proceso normal en cultivo de tejidos, ya que puede generarse cando se producen heridas o por la composición del medio de cultivo. Al lesionarse los tejidos se produce la síntesis o liberación de enzimas oxidasas, como polifenol-oxidasas, fenolasas y tirosinasas, los sustratos para estas enzimas pueden variar dependiendo del tejido, pero comúnmente son la tirosina o fenoles; este estrés provocado por heridas hace que las enzimas entren en contacto con el sustrato y, por lo general, termine desencadenando la muerte del explante.

Si bien, en el ensayo IV se formaron y desarrollaron yemas y brotes, la longitud de los mismos fue corta, aumentando posteriormente cuando se cultivaron en medio MS sin reguladores de crecimiento; esta observación también ha sido reportada para Dyckia maritima Baker (Lopes da Silva et al. 2004) y D. distachya (Pompelli \& Guerra 2005), en las cuales, tras el cultivo de explantes en medio MS y Knudson los brotes mostraron un crecimiento espontáneo.

En bromelias las respuestas morfogenéticas in vitro de diferentes tipos de explantes, generalmente están asociadas con organogénesis directa conducente a la producción de brotes (Carneiro et al. 1999). Al parecer, los brotes formados en todos los ensayos realizados en este trabajo fueron de origen adventicio directo (no hubo formación de callo), conforme a lo citado por Viehmannova et al. (2016) para P. berteroniana, en la cual, la formación de brotes adventicios inició en la parte basal de los explantes en todos los tratamientos ensayados; a partir de entonces, los brotes se desarrollaron asincrónicamente a través del experimento, dando como resultado la formación de un grupo compuesto por rosetas de diversos tamaños. No obstante, en $P$. trianae, en algunos tratamientos también se observó el desarrollo de brotes axilares; sin embargo, precisar con exactitud el origen de las yemas requiere, al menos observaciones histológicas. Según George et al. (2008) la ventaja de que se produzcan brotes adventicios se debe a que la tasa de multiplicación es mayor que la de brotes axilares, tal como se registró en los ensayos de proliferación realizados en este trabajo.

Los resultados obtenidos en la etapa de enraizamiento mostraron que el medio $\mathrm{MS} / 2$, solo y/o en presencia de auxinas, promovió la formación de raíces de aspecto delgado (excepto las desarrolladas en presencia de ANA); según Grattapaglia y Machado (1998), se ha propuesto que los medios diluidos pueden mejorar el enraizamiento, y que la adición de auxinas con altas concentraciones de sales, suelen presentar un efecto inhibitorio del enraizamiento, afectando especialmente la elongación de raíces.

En muchas especies propagadas in vitro se conoce ampliamente que el empleo de auxinas es indispensable para la formación de raíces antes de la aclimatización de las plántulas, siendo el AIB y el ANA las auxinas más empleadas, debido a su papel en la inducción y formación de tejido meristemático, promoviendo el desarrollo de primordios radicales (Hartmann \& Kester 1998).

Rodrigues et al. (2013) obtuvieron para Neoregelia concéntrica (Vellozo) L.B. Smith una mayor tasa de enraizamiento en presencia de ANA después de 30 días de cultivo, independientemente de la concentración; pero después de 60 días, la tasa de enraizamiento con ANA y con AIB no presentó diferencias significativas, reportándose valores muy similares para las dos auxinas; sin embargo, el mayor número de raíces se registró en presencia de concentraciones superiores o iguales a $2.0 \mu \mathrm{M}$ de ANA (Rodrigues et al. 2013), concentraciones también recomendadas por Pérez et al. (2013) para Hohengergia penduliflora (A.Rich.) Mez. Los resultados de número y longitud de raíces registrados para $P$. trianae concuerdan con los obtenidos en $P$. berteroniana (Viehmannova et al. 2016) evidenciándose que los brotes tratados con ANA formaron mayor número de raíces, de menor longitud, que los tratados con AIB.

En Vriesea scalaris (Lopes da Silva et al. 2009) y en Dyckia agudensis Irgang \& Sobral (Lopes da Silva et al. 2007), así como en otras bromelias, el medio MS sin reguladores de crecimiento ha promovido enraizamiento con valores promedio iguales o superiores al 48\%; de forma semejante, para $P$. trianae se registró $70 \%$ de brotes enraizados. Rodrigues et al. (2013), han atribuido los resultados de enraizamiento al gran potencial rizogénico de algunas bromelias; es decir, que la concentración de auxina endógena de dichas especies, principalmente de ácido 3-indolacético (AIA), es suficiente para producir raíces (Rodrigues et al. 2013).

Considerando lo anterior y debido, tanto a la facilidad de enraizamiento como a la apariencia de las raíces que se desarrollan, se seleccionó al MS/2, como el más adecuado para el enraizamiento in vitro de P. trianae; además, su utilización podría disminuir los costos del cultivo durante esta fase.

En cuanto a la fase de endurecimiento, la eliminación gradual del plástico extensible con el que se cubrieron los recipientes al comienzo del proceso, favoreció el establecimiento de las plántulas de $P$. trianae en condiciones de invernadero, garantizando no solo su desarrollo sino la funcionalidad de sus raíces; el efecto de la cubierta está relacionado con el control de la transpiración, evitando la muerte de plántulas por deshidratación (Mrogins- 
ki et al. 2010); esta observación es apoyada por Olmos et al. (2010), quienes han indicado que la aclimatización gradual, en un ambiente adecuado de humedad relativa y temperatura, es una fase fundamental que permite recuperar las características morfológicas y fisiológicas normales de las plantas.

Las plántulas de P. trianae mostraron un desarrollaron vigoroso en el sustrato compuesto por tierra:turba en proporción 2:1, contrario a lo observado en el sustrato tierra:capote. Según Smith y Downs (1974) los tipos de sustrato utilizados para bromelias generalmente corresponden a mezclas de musgo, turba, grava, fibra de coco o vermiculita, entre otros (Castillo 2014).

De otro lado, con el fin de tener un acercamiento a aspectos citogenéticos de la especie en estudio, debe tenerse en cuenta que, a la fecha, no se encontraron trabajos sobre recuento cromosómico en $P$. trianae, por tanto, el presente estudio reporta las primeras observaciones citogenéticas básicas de $P$. trianae. El número cromosómico de 50 es consistente con el número básico $\mathrm{x}=25$, determinado para la familia Bromeliaceae, en la cual la mayoría de géneros tienden a $2 \mathrm{n}=50$ (Brown \& Gilmartin 1989, Brown et al. 1997, Cotias et al. 2000, Gitaí et al. 2005).

Marchant (1967), luego de estudiar varias especies de Bromeliaceae sugirió la homogeneidad citogenética dentro de la familia, en la que la mayoría de las especies mostraron un número básico de cromosomas $\mathrm{x}=25$; no obstante, algunas excepciones han sido encontradas en la subfamilia Bromelioideae, en el género Cryptanthus cuyos miembros presentan $2 \mathrm{n}=34$, y Aechmea tillandsioides Baker con $2 \mathrm{n}=42$ y otras subfamilias como Pitcairnioideae, en el género Dyckya $2 \mathrm{n}=100$.

De la misma manera, Brown y Gilmartin (1989), Brown et al. (1997), Cotias et al. (2000) estudiaron especies de las tres subfamilias, encontrando para la mayoría el predominio de $\mathrm{n}=$ 25; también reportan algunas excepciones, como por ejemplo la especie triploide Ananas ananassoides (Baker) L.B.Sm. ( $2 \mathrm{n}=$ 25), el tetraploide Tillandsia butzii Mez. $(2 \mathrm{n}=100)$, el hexaploide Fosterella villosuta $(2 \mathrm{n}=150)$, Bromelia laciniosa Mart. ex Schult.f. $(2 \mathrm{n}=150)$, Cryptanthus bahianus L.B. Smith $(2 \mathrm{n}=$ $34+1-4 \mathrm{~B})$, Hoenbergia aff. ulticulosa $(2 \mathrm{n}=50+2 \mathrm{~B})$, Neoglaziovia variegata Mez. $(2 \mathrm{n}=100)$, Ortophytum burle-maxii L.B.Sm. \& Read $(2 \mathrm{n}=100)$ y Ortophytum maracaense $(2 \mathrm{n}=150)$.

Dentro de la subfamilia Pitcairnioideae, a la cual pertenece el género Puya, se ha mencionado la mayor homogeneidad de números cromosómicos (Brown \& Gilmartin 1989, Gitaí et al. 2005), aunque se reporta como la subfamilia con el menor número de especies estudiadas en aspectos citogenéticos; según Gitaí et al. (2005), solamente 48 especies de 9 géneros se habían estudiado, y en la actualidad solo se encontró un registro adicional, P. berteroniana (Viehmannova et al. 2016). En el género Puya dicha homogeneidad se ve representada en las especies que han sido estudiadas como $P$. eringyoides Andre, $P$. flocossa (Linden) E. Morren, P. lilloi Castell, P. spathacea (Griseb.) Mez, encontrándose el número cromosómico básico propuesto (Brown \& Gilmartin 1989, Gitaí et al. 2005), y en las especies P. cardaenasii L.B. Smith, P. raymondii Harms, P. spathacea Mez. un número cromosómico $2 \mathrm{n}=50$, solamente variando la especie P. chilensis Molina con 2n= 48 (Gitaí et al. 2005).

Zanella et al. (2012) señala que los cromosomas en bromelias son extremadamente pequeńos, que van aproximadamente de $0.21 \mathrm{a} 2.72 \mu \mathrm{m}$. En las especies de la subfamilia Pitcairnioideae se han observado cromosomas pequeños y de tamaño uniforme, con una variación entre 0.53 a $1.07 \mu \mathrm{m}$, contrario a un mayor tamaño observado en la subfamilia Tillandsioideae, y una diversidad de tamaños en Bromelioideae (Gitaí et al. 2005). En este mismo trabajo en la especie Puya coerulea Lindley con $2 \mathrm{n}=50$, se encontraron cromosomas de tamaño de 0.75 a 1.50 $\mu \mathrm{m}$, caracterizándose por ser esferoides a puntiformes, siendo los cromosomas de tamaño más o menos homogéneo, similares a los cromosomas observados de $P$. trianae.

Debe tenerse en cuenta que debido al gran número y pequeño tamaño de los cromosomas de $P$. trianae, fácilmente se puede incurrir en errores de conteo. En general, para la mayoría de las especies de la familia Bromeliaceae, el análisis morfológico de los cromosomas se ha dificultado, debido a la poca capacidad de tinción, el contenido citoplasmático muy coloreable, el alto número y el pequeño tamaño de los cromosomas (Gitaí et al. 2005, Nunes et al. 2013, Zanella et al. 2012), siendo esta última característica un obstáculo para una confiable caracterización citogenética en la mayoría de plantas (Nunes et al. 2013).

Finalmente, de acuerdo con el conteo cromosómico realizado y los datos de la literatura científica revisada, se indica que los regenerantes obtenidos puede ser diploides estables, lo cual confirmaría la eficacia del sistema de micropropagación optimizado en el presente estudio, satisfaciendo la sugerencia realizada por Viehmannova et al. (2016), quienes han indicado que es recomendable completar cada protocolo de micropropagación con un sistema confiable de evaluación de plantas cultivadas in vitro para determinar el éxito del mismo.

\section{Conclusión}

El presente estudio constituye la primera investigación sobre micropropagación y citogenética básica de $P$. trianae, planta silvestre que debe ser conservada y que tiene potencial para uso ornamental. Los aportes realizados con el fin de producir masivamente materiales vegetales con características genéticas estables son consistentes y efectivos, y, además, constituyen un avance para la aplicación de estas herramientas biotecnológicas en especies afines, con poblaciones pequeñas y en peligro de extinción, con el objetivo de conservar el germoplasma vegetal.

\section{Agradecimientos}

Al Laboratorio de Cultivo de Tejidos Vegetales Bioplasma de la Universidad Pedagógica y Tecnológica de Colombia por la financiación de la investigación y al Grupo de Investigación Bioplasma-UPTC por el acompańamiento en la ejecución del mismo.

\section{Literatura citada}

Al-saif A., A. Hossain, \& R. Taha. 2011. Effects of benzylaminopurine and naphthalene acetic acid on proliferation and shoot growth of pineapple (Ananas comosus L. Merr) in vitro. African Journal of Biotechnology 10(27):5291-5295. https://doi.org/10.5897/AJB11.370

Alves G. 2000. Micropropagação e conservação de Vriesea reitzii e Vriesea friburgensis var. Paludosa. [Tesis]. [Florianápolis]: Universidade Federal de Santa Catarina.

Aoyama E., A. Lima, \& D. Vidal. 2012. Propagação em Bromeliaceae: Germinação de Sementes e Cultivo in vitro. Enciclopédia Biosfera 8(15):1452-1471.

Azofeifa Á. 2009. Problemas de oxidación y oscurecimiento de explantes cultivados in vitro. Agronomía Mesoamericana 20(1):153-175. https://doi.org/10.15517/am.v20i1.4990 
Benson, E. 1999. Conservation of endangered plants. In Benson, E., editor. Plant Conservation Biotechnology. Londres: Taylor \& Francis. p. 228-241.

Benzing D., \& A. Renfrow. 1974. The mineral nutrition of Bromeliaceae. Botanical Gazette 135(4):281-288. https://doi. org/10.1086/336762

Betancur J., \& N. García. 2006. Las Bromelias. En García, N. \& Galeano, G. editores. Libro Rojo de Plantas de Colombia. Volumen 3: Las bromelias, las labiadas y las pasifloras. Serie Libros Rojos de Especies Amenazadas de Colombia. Bogotá D.C: Instituto Alexander von Humboldt; Instituto de Ciencias Naturales de la Universidad Nacional de Colombia; Ministerio de Ambiente, Vivienda y Desarrollo Territorial. p. 51-384.

Brown G., \& A. Gilmartin. 1989. Chromosome numbers in Bromeliaceae. American Journal of Botany 76(5):657-665. https:// doi.org/10.1002/j.1537-2197.1989.tb11361.x

Brown G., C. Palací, \& H. Luther. 1997. Chromosome numbers in Bromeliaceae. Orchids 18(1):85-88.

Cabello A., \& D. Suazo. 2007. Algunos antecedentes sobre propagación del género Puya (Bromeliaceae) en Chile. En Legassa M., \& A. Moreira. editores. Revista del Jardín Botánico Chagual Chile: Corporación Jardín Botánico Chagual. Vol. 5. p. 65-71.

Carneiro L., R. Araújo, G. Brito, M. Fonseca, A. Costa, O. Crocomo, \& E. Mansur. 1999. In vitro regeneration from leaf explants of Neoregelia cruenta (R. Graham) L. B. Smith , an endemic bromeliad from Eastern Brazil. Plant Cell, Tissue and Organ Culture 55:79-83. https://doi. org/10.1023/A:1006186627580

Casta-eda M. 2008. Propagación y Conservación de Lirio de Todos Santos Laelia anceps Lindl. subsp. anceps f. semialba (Orchidaceae) a través del cultivo de tejidos. [Tesis]. [Xalapa]: Universidad Veracruzana.

Castillo V. 2014. Germinación de semillas y sobrevivencia de plántulas de tres especies de Tillandsia y dos de Hechtia. [Tesis]. [México]: Colegio de Postgraduados.

Cotias A., J. Aquino, M. Cortizo, J. Souza, \& M. Silva. 2000. Chromosome numbers in Bromeliaceae. Genetics and Molecular Biology 23(1):173-177. https://doi.org/10.1590/S141547572000000100032

Cotias A., J. Assis, G. Ceita, A. Palmeira, \& M. Guedes. 2004. Chromosome Number for Bromeliaceae Species Occurring in Brazil. Cytologia 69(2):161-166. https://doi.org/10.1508/ cytologia.69.161

Dal-Vesco B., P. Vieira, J. Corredor, R. Pescador, L. Welter, \& M. Guerra. 2014. Induction and development of nodular cluster cultures in Vriesea reitzii (Leme and Costa), an endangered bromeliad from the Brazilian Atlantic Forest. Journal of Horticultural Science \& Biotechnology 89(5):542-548. https://doi.org/10.1080/14620316.2014.11513118.

Fuenzalida R. 2003. Propagación in vitro de especies endémicas del Parque Nacional Archipiélago de Juan Fernández, Isla Robinson Crusoe. [Tesis]. [Chile]: Escuela de Agronomía. Pontificia Universidad de Valparaiso, Chile.

George E., M. Hall, \& G. Klerk. 2008. Plant propagation by tissue culture (The Backgr, Vol. 1). Netherlands: Springer.

Gitaí J., R. Horres, \& A. Benko. 2005. Chromosomal features and evolution of Bromeliaceae. Plant Systematics and Evolution 253:65-68. https://doi.org/10.1007/s00606-005-0306-8

Gitaí J. \& AM. Benko-Iseppon. 2006. Contribuição de Características Citogenéticas e Moleculares à Sistemática de Bromeliaceae. Tese (Doutorado). Programa de Pós-Graduaçáo em Ciências Biológicas, Universidade Federal de Pernambuco, Recife. P. 114. https://repositorio.ufpe.br/handle/123456789/2075

Gonçalves S. 2010. Reguladores vegetais no desenvolvimento in vitro de bromélia (Aechmea blanchetiana). [Tesis]. [Botucatu]:Universida de Estadual Paulista.

Grattapaglia D., \& M. Machado. 1998. Micropropagação. En Torres A., L. Caldas, \& J. Buso. editores. Cultura de tecidos e transformação genética de plantas. Brasília: Embrapa-Sp. p. $183-260$

Grau A., S. Gómez, \& E. Aráoz. 2010. Puyas Andinas. Ciencia Hoy 20(118):8-15.
Guo B., B. Abbasi, A. Zeb, L. Xu, \& Y. Wei. 2011. Thidiazuron: A multi-dimensional plant growth regulator. African Journal of Biotechnology 10(45):8984-9000. https://doi.org/10.5897/ AJB11.636

Hartmann H., \& D. Kester. 1998. Propagación de Plantas: Principios y Prácticas. México D. F.: Compa-ía Editorial Continental.

Huetteman C. \& J. Preece. 1993. Thidiazuron: a potent cytokinin for woody plant tissue culture. Plant Cell, Tissue and Organ Culture 33(2):105-119. https://doi.org/10.1007/ BF01983223

Jha T., \& B. Ghosh. 2005. Plant tissue culture : basic and applied. India: Universities Press (India) Ltd.

Llambí L., A. Soto, R. Celleri, B. De Bievre, B. Ochoa, \& P. Borja. 2012. Páramos Andinos: Ecología, hidrología y suelos de páramos. IAvH, FONAG, USAID, Instito de Monta-a, ICAE, GEF, UNEP, CONDENSAN. P. 271.

Lopes da Silva A., D. Bisognin, E. Dornelles, J. Walter, \& E. Franco. 2004. Ensaios sobre o alongamento de brotos laterais de Dyckia maritima Baker dispostos em agrupamentos - Bromeliaceae. Caderno de Pesquisa Série Biologia 16(2):37-46.

Lopes da Silva A., E. Bortoluzzi, D. Bisognin, E. Henz, \& M. Horbach. 2007. Micropropagation of Dyckia agudensis Irgang \& Sobral - an extinction threatened bromeliad. Iheringia, Sér. Bot. 62(1-2):39-43.

Lopes da Silva A., J. Da Luz, G. Bomfim, C. De Carvalho, M. Ruzza, L. Biasi, G. Newton, \& C. Soccol. 2012. Micropropagation of Nidularium innocentii lem. and Nidularium procerum lindm (Bromeliaceae). Pak. J. Bot. 44(3):1095-1101.

Marchant C. 1967. Chromosome evolution in the Bromeliaceae. Kew Bull 21:161-168. https://doi.org/10.2307/4108461

Miranda M., J. Arellano, B. Salazar, F. Hernández, R. Quero, \& L. Pérez. 2007. Bases para el manejo comunitario de Bromelias Ornamentales. México D. F.: D.R. Grupo Autónomo para la Investigación Ambiental A.C.

Morales M., P. Gil, Díaz, L. Sanabria, \& L. Torres. 2011. Creación del Banco de Germiplasma, Vivero Regional y Propagación de Epeletia paipana en la Zona de Influencia de Parque Natural Municipal Ranchería. Convenio de Cooperación Número 083-2009. Tunja, Colombia.

Mroginski L., P. Sansberro, \& E. Flaschland. 2010. Establecimiento de cultivos de tejidos vegetales. En Levitus G., V. Echenique, C. Rubinstein, E. Hopp, \& L. Mroginski. editores. Biotecnología y mejoramiento vegetal II. Argentina: Instituto Nacional de Tecnología Agropecuaria (INTA). p. 17-25.

Murashige,T., \& F. Skoog. 1962. A revised medium for rapid growth and bioassays with tobacco tissue cultures. Physiol. Plant. 15:473479. https://doi.org/10.1111/j.1399-3054.1962.tb08052.x

Nunes C., E. Nogueira, A. Gontijo, C. Carvalho, \& W. Clarindo. 2013. The first karyogram of a Bromeliaceae species: an allopolyploid genome. Plant Systematics and Evolution 299(6):1-8. https://doi.org/10.1007/s00606-013-0784-z

Olmos S., G. Luciani, \& E. Galdeano. 2010. Micropropagación. Biotecnología y mejoramiento vegetal. En Levitus G., V. Echenique, C. Rubinstein, E. Hopp, \& L. Mroginski. editores. Biotecnología y mejoramiento vegetal II. Argentina: Instituto Nacional de Tecnología Agropecuaria (INTA). p. 352-362.

Pedroza J., \& A. Bejarano. 2008. Propagación vegetatita in vitro de Puya santosii. Revista Colombiana de Biotecnología 10(1): 36-48.

Pérez A., T. Laudat, M. Mora, C. Carvajal, C. Aragón, J. González, M. Escalona, M. Daquinta, R. Trujillo, \& M. Hernández. 2013. Micropropagation of Hohenbergia penduliflora (A. Rich.) Mez. for sustainable production of plant proteases. Acta Physiologiae Plantarum 35(8):2525-2537. https://doi. org/10.1007/s11738-013-1288-8

Perez J., N. Albany, J. Vilchez, S. Sierralta, \& M. De, Molina. 2010. Efecto del medio de cultivo en la multiplicación in vitro de Aloe barbadensis Mill. Rev. Fac. Agron. (LUZ) 27:447-459.

Poggio L., G. González, M. Ferrari, A. García, A. Wulff., E. Greizerstein, P. Tómas, \& G. Schrauf. 2010. Aportes de la citogenética al estudio de genomas vegetales. En Levitus G., V. Echenique, C. Rubinstein, E. Hopp, \& L. Mroginski. editores. Biotecnología y mejoramiento vegetal II. Argentina: Instituto Nacional de Tecnología Agropecuaria (INTA). p. 379-380. 
Pompelli M. \& M. Guerra. 2005. Micropropagation enables the mass propagation and conservation of Dyckia distachya Hassler. Crop Breeding and Applied Biotechnology 5:117-126. https://doi.org/10.12702/1984-7033.v05n01a16.

Quiala E., G. Montalvo, \& J. Matos. 2004. Empleo de la Biotecnología vegetal para la propagación de cactáceas amenazadas. Biotecnología Vegetal 4(4):195-199.

Rodrigues J., E. Romais, R. Sobreira, B. Régis, \& G. Magevski. 2013. Effect of synthetic auxins on in vitro and ex vitro bromeliad rooting. Pesq. Agropec. Trop., Goiânia 43(2):138-146.

Scherer R., A. Correa, H. Pacheco, L. Dal, D. Steinmacher, \& M. Guerra. 2013. Nodule cluster cultures and temporary immersion bioreactors as a high performance micropropagation strategy in pineapple (Ananas comosus var. comosus). Scientia Horticulturae 151:38-45. https://doi.org/10.1016/j. scienta.2012.11.027.

Silveira D., F. Duarte, D. Souza, C. Pelacani, A. Da-Silva, C. Alberto, C. Da-Silva, \& J. Ferreira. 2009. Micropropagation and in Vitro Conservation of Neoglaziovia variegata (Arr. Cam.) Mez., a Fiber Producing Bromeliad from Brazil. Brazilian Archives of Biology and Technology and International Journal 52(4):923-932. https://doi.org/10.1590/S151689132009000400016

Smith L. \& R. Downs. 1974. Pitcairnioideae-Bromeliaceae. Flora Neotropica. Monograph 14. New York: Hafner Press. New York: Hafner Press.

Soares D. 2009. Micropropagação da bromélia ornamental Acanthostachys strobilacea (Schultz F.) Klotzsch e a influência do etileno. [Tesis]. [São Paulo]: Instituto de Botânica da Secretaria de Estado do Meio Ambiente.

Soares R., J. Pinto, S. Rosado, L. Domiciano, \& R. Monteiro. 2008. Influência do meio de cultura na germinação de sementes in vitro e taxa de multiplicaçáo de Melissa officinalis L. Ceres 55(3):160-167.
Suárez F. 2011. Micropropagación in vitro de Pi-a (Ananas comosus L. Merril) Híbrido MD-2, a partir de Cortes de Yemas Laterales y Apicales. [Tesis]. [Sangolquí]: Escuela Politécnica del Ejército.

Vargas O., L. Melgarejo, V. Pérez, N. Rodríguez, \& J. Torres. 2014. Semillas de Plantas de Páramo: Ecología y Métodos de Germinación Aplicados a la Restauración Ecológica. En Vargas, O., \& V. Pérez. editores. Bogotá D.C: Universidad Nacional de Colombia.

Viehmannova I., P. Hlasna, J. Vitamvas, P. Streblova, \& J. Kisilova. 2016. Micropropagation of a giant ornamental bromeliad Puya berteroniana through adventitious shoots and assessment of their genetic stability through ISSR primers and flow cytometry. Plant Cell, Tissue and Organ Culture (PCTOC) 125(2):293-302. https://doi.org/10.1007/ s11240-016-0949-x.

Walter K., \& H. Gillett. 1998. 1997 IUCN Red List of Threatened Plants. Compiled by the World Conservation Monitoring Centre. Switzerland and Cambridge.

Zamora A., \& D. Juárez. 2008. Micropropagación en Pi-a (Ananas comosus (L.) Merr.) Cultivar MD-2. [Tesis]. [Managua]: Universidad Nacional Agraria.

Zanella C., A. Janke, C. Palma, E. Kaltchuk, F. Pinheiro, G. Paggi, L. Soares, M. Goetze, M. Büttow, \& F. Bered. 2012. Genetics, evolution and conservation of Bromeliaceae. Genetics and Molecular Biology 35(4), 1020-1026. https://doi. org/10.1590/S1415-47572012000600017 